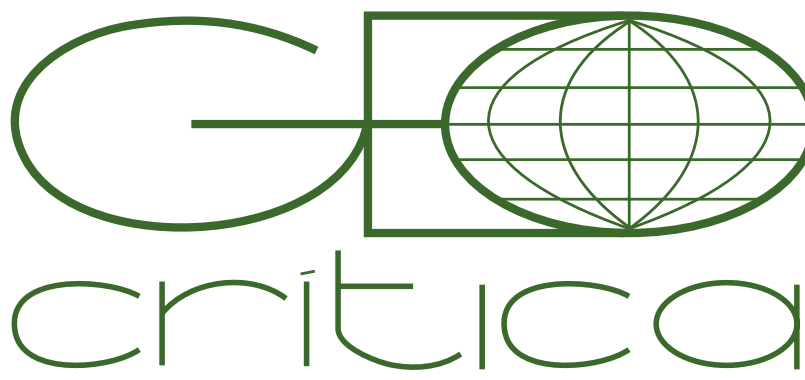

\section{Scripta Nova}

Revista Electrónica de Geografía y Ciencias Sociales Universidad de Barcelona

15 de enero de 2017

\title{
PUEBLOS INDÍGENAS EN LA FRONTERA BONAERENSE. LOS ASENTAMIENTOS DE "INDIOS AMIGOS" DURANTE EL SIGLO XIX
}

\author{
Melina Yuln \\ Instituto de Investigaciones en Historia, Teoría y Praxis de la Arquitectura y la Ciudad \\ Facultad de Arquitectura y Urbanismo- Universidad Nacional de La Plata \\ melinayuln@yahoo.com.ar
}

Recibido: 7 de octubre de 2014. Aceptado: 18 de junio de 2015.

\begin{abstract}
Resumen. Pueblos indígenas en la frontera bonaerense. Los asentamientos de "indios amigos" durante el siglo XIX

Durante los últimos años, las investigaciones de historia territorial han introducido un nuevo abordaje metodológico que articuló aspectos históricos clásicos con el uso crítico de fuentes documentales gráficas para el estudio del territorio de la provincia de Buenos Aires. De este modo, la organización del territorio -su poblamiento, la conformación física de pueblos, asentamientos o colonias, su subdivisión o sus representaciones cartográficas- puede examinarse a partir del análisis del plano o el mapa.

Este trabajo aborda los procesos de construcción territorial en la pampa bonaerense durante la segunda mitad del siglo XIX, particularmente en torno a las modalidades de ocupación y reconocimiento de tierras -por parte del estado- a las tribus indígenas que habitaban en distintos sectores de la frontera sur y oeste.
\end{abstract}

Palabras clave: territorio, frontera, asentamientos indígenas, siglo XIX, Buenos Aires

\begin{abstract}
Indigenous peoples in Buenos Aires frontier. Settlements from "indios amigos" during the nineteenth century

In recent years, investigations of territorial history have introduced a new methodological approach articulated classics historical aspects with a critical use of graphic documental sources for the study of the territory in Buenos Aires province. Thereby, territorial organization -its populating, the physical conformation of villages, settlements or colonies, subdivision or cartographic representations- can be examined through the analysis of the plan or the map.

This paper deals with the processes of territorial construction in the Buenos Aires pampas during the second half of the nineteenth century, particularly around the modes of land occupation and recognition -by state- to the indigenous tribes who inhabited in the frontier.
\end{abstract}

Keywords: territory, frontier, indigenous settlements, nineteenth century, Buenos Aires 
Durante los últimos años, las investigaciones de historia territorial han introducido un nuevo abordaje metodológico que articuló el análisis de fuentes gráficas y escritas para el estudio del territorio de la provincia de Buenos Aires ${ }^{1 .}$ Este trabajo se basa en esas contribuciones, que conjugan diversas perspectivas analíticas para la construcción de una estructura compleja como el territorio. El enfoque aquí propuesto pretende articular aspectos históricos clásicos con el uso crítico de fuentes documentales gráficas, ya que se considera al registro gráfico un corpus documental que no ha sido debidamente explotado por los estudios históricos.

En este sentido -y acerca del análisis de las estrategias de organización territorial en la campaña bonaerense-, la historia económica, la historia rural o la etnohistoria, han abordado parcialmente el cuerpo documental y bibliográfico aquí utilizado y han trabajado tomando como base las normativas jurídicas en su intento de establecer periodos y etapas dentro de la estructura legislativa de las tierras fiscales en Argentina. Si bien existen investigaciones exhaustivas respecto de la aplicación formal de leyes y decretos sobre tierras públicas, estas indagaciones se han concentrado en el mapeo de propiedades o en estudios de estrategias legales de acceso a la tierra, ignorando, en general, el correlato propiamente físico de la implementación de estas leyes. De manera que no se dimensiona históricamente la configuración espacial, factible de ser verificada no sólo mediante los mapas y planos que constituían el registro gráfico de las normas adoptadas, sino también a partir del reconocimiento del propio terreno. Muchos de estos trabajos se han concentrado en la discusión de normas jurídicas que permitían soluciones específicas, y sin embargo no se han preguntado cuál fue la repercusión a escala territorial de los avatares sufridos durante décadas de litigios legales sobre las tierras del Estado que pasaban a manos privadas.

A partir de las carencias gráficas de esos enfoques -o de la ausencia de su problematización- se originó la necesidad de una indagación más allá de la interpretación escrita tradicional. De modo que, el estudio del territorio, la configuración de sus poblaciones, su subdivisión o sus representaciones cartográficas, no eran examinados a partir del análisis del plano o el mapa. De ahí proviene el interés que revisten los registros cartográficos cuando se pretende investigar el modo en que es organizado el territorio, en cuestiones relativas al poblamiento, a la conformación física de pueblos, asentamientos o colonias. En suma, la principal contribución a la historia del territorio -a la cual aspira este trabajo-, se halla en la reelaboración gráfica de las fuentes y en la vinculación entre fuentes gráficas y escritas, aportando así a la actualización de la literatura sobre la frontera decimonónica.

Este trabajo aborda los procesos de construcción territorial en la pampa bonaerense durante la segunda mitad del siglo XIX, particularmente en torno a las modalidades de ocupación y reconocimiento -por parte del estado- de tierras a las tribus indígenas que habitaban en distintos sectores de las fronteras sur y centro-oeste. Al

1 Aliata, 2010; Aliata y Loyola, 2010; Aliata et al, 2012; Silvestri, 1999, 2011; Silvestri et al, 2008; Pesoa Marcilla, 2012; Zweifel, 2013; Yuln, 2009, 2011, 2014. 
respecto, se hace un análisis comparativo de la situación de distintas parcialidades a las cuales les fueron otorgadas y/o reconocidas extensiones de tierra de diferentes características y superficies, teniendo en cuenta para ello el entorno ambiental, las variables económicas, culturales y simbólicas relacionadas con las prácticas y tradiciones indígenas, su vinculación con los agentes o instituciones estatales con los que interactuaron y las condiciones político-militares de la frontera que dieron marco a dichos procesos. Se analizarán los casos correspondientes a las tribus de Maicá, Melinao, Ancalao, Rondeau, Raninqueo y Coliqueo entre las décadas de 1850-1870.

Las fuentes documentales aquí utilizadas se agrupan en dos conjuntos principales de registros: el legal y el cartográfico. El primero, incluye debates y normas legislativas referidas a tierras públicas y el segundo, incorpora planos y mapas de tierras concedidas por el estado a los grupos de "indios amigos" asentados en la frontera bonaerense. De este modo, se articula el análisis de fuentes cartográficas y documentales y ello deriva en la reconstrucción planimétrica de los casos abordados.

El artículo se organiza en dos grandes apartados referidos al territorio y a las tierras de indígenas: en el primero se desarrolla la problemática de la frontera decimonónica a partir de las políticas estatales y las estrategias de territorialización durante el periodo estudiado. En el segundo, se indagan las acciones concretas del estado provincial bonaerense para la concesión de tierras a las tribus asentadas en su área de frontera y se desarrollan los diversos casos de estudio propuestos.

\section{El territorio de frontera}

Cuando se estableció el virreinato del Río de la Plata en 1776, con Buenos Aires como ciudad capital, la región pampeana cobró un nuevo valor estratégico. La frontera indígena estaba muy cerca de Buenos Aires de manera que, para los diversos gobiernos virreinales, la defensa y la seguridad de la campaña fue una preocupación constante. Para asegurar el abastecimiento de la capital, el Cabildo de Buenos Aires aconsejaba el establecimiento de pueblos en la frontera como un modo de evitar las incursiones de malones en busca de hacienda y lograr así la contención de los ganados cimarrones en la campaña circundante.

Este proceso territorial comenzó con la creación del Virreinato y la ejecución del Plan Betbezé, en el cual se proponía la fundación de fortines y una frontera armada móvil, que tuviera sucesivos progresos. Estas "líneas" eran bastante virtuales y permeables, ya que entre cada fortín existía una distancia de varias leguas ${ }^{2}$ que dificultaba el control del territorio intermedio 3 .

El fuerte o fortín era un asentamiento militar cuyas funciones básicas eran albergar la guarnición militar, proteger a los habitantes que se establecieran en los alrededores, proteger también el ganado y las caballadas de los ataques indígenas

2 La legua equivale aproximadamente a cinco kilómetros. Legua lineal = 5.199,6 metros. Fuente: Garavaglia \& Gautreau, (2011: 29).

3 La materialización de una línea propiamente dicha se ejecutó en 1876-77 con la construcción de la zanja de Alsina -de 380 km de extensión-, jalonada por 115 fortines separados entre sí por una legua de distancia. 
y asegurar así un control visual de la llanura. Si bien eran ideados por ingenieros militares de la corona española, los fortines debieron adecuarse al medio natural y la tradición constructiva local elemental. En la medida de las posibilidades de una llanura como la pampeana, el ingeniero elegía un sitio elevado -para tener un control sobre el territorio circundante- que tuviera buenos pastos y aguadas cercanas para los animales. Se levantaba un campamento con tiendas de campaña, mientras que los animales se ubicaban en corrales de 50 metros de lado, rodeados por un foso de 3 metros de ancho, aproximadamente. Luego se levantaban las viviendas provisorias de los oficiales con estructura de madera y muros de chorizo ${ }^{4}$. Al igual que los corrales de ganado, el fortín estaba rodeado por un foso y un terraplén ${ }^{5}$.

En la práctica, estas disposiciones constructivas sufrían adaptaciones drásticas ya que, tanto el medio natural como los recursos estatales, ofrecían escasas posibilidades. Hay que recordar que junto con las tropas militares se asentaban sus familias -mujeres y niños- con lo cual el "campamento militar", originalmente ligado a un carácter provisorio, era más bien un asentamiento poblacional permanente. El fortín tuvo un rol protagónico en la estructuración del territorio, ya que a partir de él se desarrollaron algunas colonias agrícolo-ganaderas y luego pueblos y ciudades, sobre la base de su población estable (Figura 1).

Si bien la frontera representaba el núcleo conflictivo de la cuestión territorial aún antes de la independencia, fue a partir de 1852 que las incursiones indígenas se incrementaron y la frontera pasó a ser un tema fundamental, al punto que se le dedicaba un apartado en los mensajes presidenciales de apertura de las sesiones legislativas, desde Rivadavia en adelante hasta Roca. Junto con las cuestiones referidas a la política exterior e interior o a la economía y la justicia, la frontera siempre era mencionada, a veces como el lugar de resistencia contra el indígena y de acantonamiento de las milicias, a veces como un escollo que el poder ejecutivo esperaba superar en pos del beneficio territorial de la nación. Pero esa "frontera" no tenía un lugar establecido ya que variaba, moviéndose de un lugar a otro, como el espacio fluctuante que representaba -sobre todo fue a partir de la presidencia de Mitre, que los presidentes en cada discurso anual hacían referencia a la necesidad de una nueva frontera ${ }^{6}$.

\section{Políticas territoriales en la frontera}

Los debates legislativos también señalaban la necesidad de ampliar la extensión del territorio productivo. En el proceso de transformación del Estado moderno, que se consolidaría en la década de 1880, el avance progresivo de la frontera se

4 Mezcla compuesta de barro y paja para construir las paredes.

5 López Osornio, 1944, p. 85 y ss.; Raone, 1969, p. 40 y ss.; Mayo y Latrubesse, 1998, p. 65-70; Ramos, 2004, p. 99-100.

6 Ver H. Mabragaña (1910), Los mensajes. Historia del desenvolvimiento de la Nación Argentina redactada cronológicamente por sus gobernantes, 1810-1910, Tomos III y IV, Comisión Nacional del Centenario, Talleres Gráficos de la Compañía Gral. de Fósforos, Buenos Aires. 
produjo hacia el oeste de la actual provincia de Buenos Aires y hacia el sur, sobre las provincias centrales y la Patagonia. Desde la década de 1860 en las cámaras de representantes se debatían proyectos para avanzar sobre la frontera sur, pero desde el Ministerio de Guerra los distintos ministros hacían hincapié en la dificultad que representaba esta medida. Si bien alentaban la iniciativa, también alegaban la necesidad de conformación de un ejército nacional para tal empresa, además de la organización de una expedición no sólo desde el punto de vista militar sino también científico, de relevamiento y reconocimiento territorial.

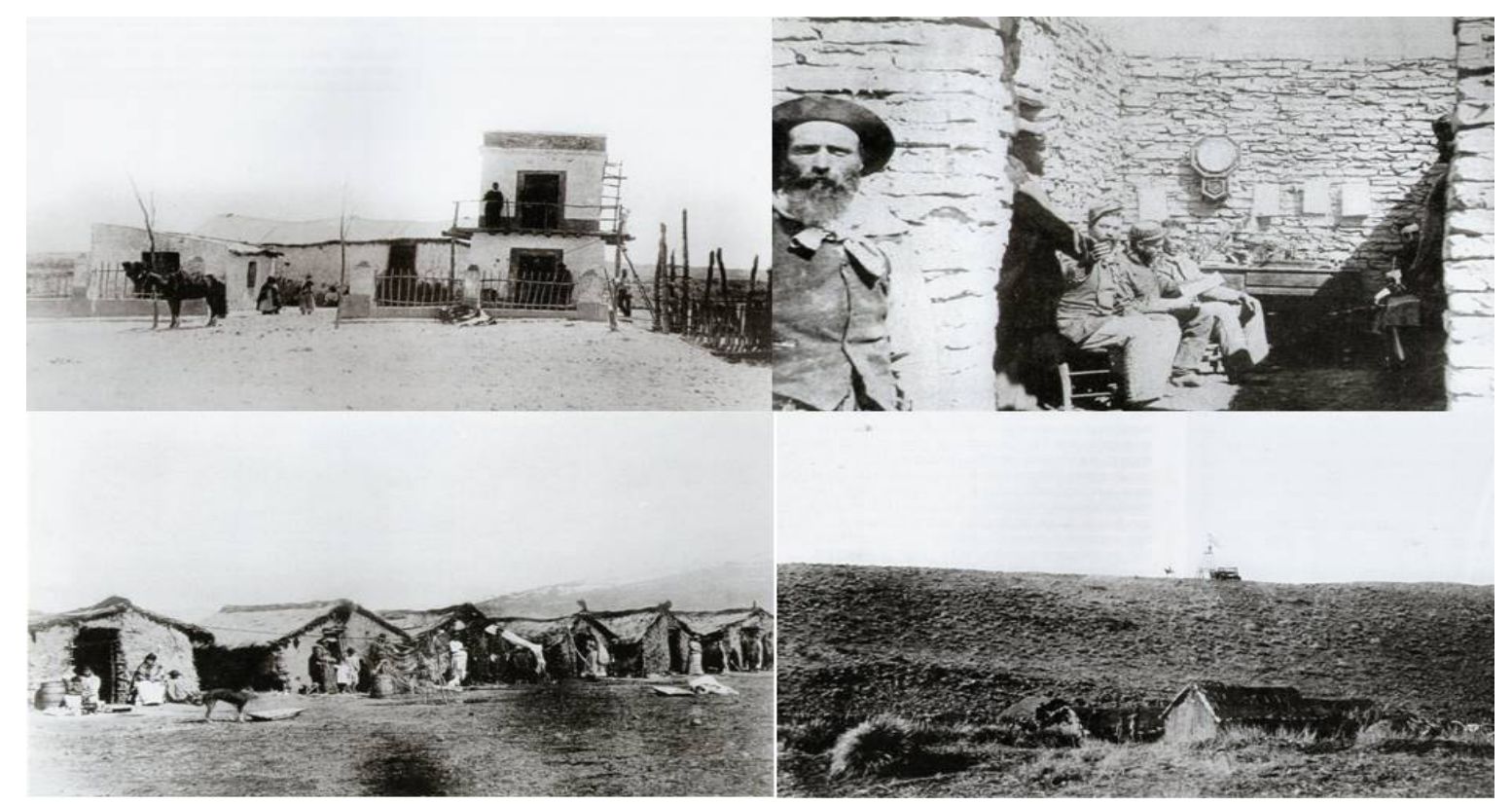

Figura 1. Fotografías de Fortines en la Patagonia. Arriba: Fortín Limay (actual provincia de Neuquén). Comandancia y oficina telegráfica.

Abajo: Cuartel de Ñorquín (actual provincia de Neuquén). Viviendas de las familias de soldados y mangrullo. La precariedad de las construcciones y su dudosa estabilidad constructiva demuestran la falta de recursos y las soluciones adoptadas.

Fuente: Álbum de los ingenieros Encina y Moreno durante una expedición patagónica de 1883 (Vezub, 2002).

En vista de la existencia de una ley del congreso que exigía al Poder Ejecutivo mover la frontera hacia el oeste, entre las décadas de 1860-70 se presentaron diversos proyectos de ley relativos a la campaña y en particular a la frontera. Los objetivos de estas propuestas tendían a establecer una nueva línea contra los indígenas del sur o establecer su corrimiento hasta el río Negro; otros apuntaban a regularizar los tratados de paz, la sanción de leyes que dieran seguridad a los productores o a subsanar la insuficiencia e ineficacia de las fuerzas de frontera ${ }^{7}$. Durante la presidencia de

7 BHCN, Congreso Nacional, Cámara de Senadores, Diario de Sesiones, 1867, p.181. Ver Diarios de sesiones 1864, 1868, 1869, 1870; HCDN, Archivo Parlamentario: Diputados (1860), Caja No 2 Exp.:23 Letra: D; (1863) Caja No 2 Exp.:24 Letra: D; (1870) Exp.: 17 Letra: D; (1872) (1879) Libro No 7; Senado (1862) Exp.:13 Letra: S; Exp.: 7 Letra: S; (1867) Caja No 6 Exp.:5 Letra: S; Particulares (1872) Caja No 18 Exp.:11 Letra: P. 
Sarmiento se presentó un proyecto de ley para ocupar y colonizar el territorio comprendido entre el Río Negro y la frontera sur de Córdoba, a la altura del Río Quinto. Pero en 1870 no estaban dadas las condiciones para llevar adelante una empresa que recién se concretaría nueve años más tarde. En ese año el ministro de Guerra y Marina, Martín de Gainza, decía que

“para ocupar la línea del río Negro se necesita primero tener un ejército. Desgraciadamente nuestro ejército no se compone sino de cuadros de jefes y oficiales y no se puede lanzar al desierto un ejército que no tenga una base más sólida porque seria exponerlo a una desorganización total, con el desierto y el enemigo por enfrente y con el desierto y el enemigo por la espalda. ¿Sabemos acaso (...) si podemos abastecer ese ejército con toda la regularidad que es necesaria? (...) ¿quién conoce el río Negro, quién conoce ese territorio? (...) Por dónde (abastecemos) nuestra línea en el río Negro ¿Por Mendoza? ¿Qué distancia hay de Mendoza? Nadie lo sabe porque son territorios que no han sido explorados"

Se pone así de manifiesto el carácter dinámico de una frontera que, más allá de la defensa militar, constituía un ámbito en constante mutación en el cual sus actores principales establecían una relación de interacción con el territorio eventualmente ocupado. Los estudios etnohistóricos recientes proponen a la frontera como un espacio social diferenciado, tanto del mundo indígena como del mundo hispano-criollo. Es decir, se le reconoce su lógica particular ya que se trata de un espacio que no puede ser encasillado dentro de la órbita estatal ni de la población nativa9

En este sentido, el aporte de Mansilla, con su expedición de 1871, contribuyó a reforzar la idea de frontera como ámbito ambiguo y de contornos variables. Pero también a desmitificar la idea de ruptura entre las nociones de civilización o barbarie, que encasillaba en esta última y de manera indiscutida a la vida indígena en general. Mansilla describió lugares, costumbres y acciones que indicaron el fuerte arraigo de los indígenas no sólo por la tierra sino por la producción material de sus asentamientos, señalando que el nomadismo -además de representar una forma de vida ancestralmente heredada- también respondía a un mecanismo de defensa contra los avances militares.

\section{El Negocio Pacífico prolongado}

El Negocio Pacífico de Indios fue una política iniciada en el período borbónico. Durante el gobierno de Rosas este sistema consistió en el acuerdo de tratados de paz con los grupos indígenas "aliados" y la incorporación de grupos "amigos" - principalmente pampas y borogas- que prestaban servicios militares alrededor de los fuertes.

8 BHCN, Congreso Nacional, Cámara de Senadores, Diario de Sesiones, 28 de Junio de 1870, p.138.

9 Mandrini, 2006, p. 63 y ss.; Navarro Floria, 2001, p.351. 
Luego de la Campaña al Desierto, Rosas había establecido diferencias de relación con las tribus indígenas, considerando indios enemigos a los aliados de sus adversarios políticos e indios amigos a aquellos grupos que resultaban funcionales a sus estrategias de poblamiento. Esta política logró estabilizar las relaciones interétnicas a través de la inclusión de dos tipos de facciones indígenas. Por un lado, las aliadas, que pretendían mantener su autonomía política y territorial -cuestión que entró en conflicto con la pretensión de mayor obediencia que buscaba el Estado provincial-; y las tribus amigas, que eran grupos reducidos, asentados al interior de la frontera y funcionaban como fuerza militar auxiliar a cambio de raciones y sueldos, aún cuando esto significara perder la autonomía. Este mecanismo de negociación, que oscilaba entre la represión y la persuasión, se mantuvo hasta el final del régimen rosista ${ }^{10}$.

Rosas había logrado liberar la frontera de las tribus ranqueles hostiles a su gobierno, de modo que luego de la campaña de 1833 sobrevino un período de paz. Pero después de 1852, -finalizado el gobierno de Rosas- se inició una política más agresiva, ya que se avanzó sobre los territorios indígenas con una nueva línea de fortines, a la vez que se suspendieron las raciones a las tribus catrieleras de Tapalqué, en el sur de la Provincia de Buenos Aires. Durante la década de 1850 los malones incursionaron nuevamente sobre los pueblos fronterizos. La situación se suavizó durante 1856, con la entrega de tierras a Catriel en la zona de Azul y esto provocó la separación entre Calfucurá y los caciques "amigos"11.

Si bien algunas de estas parcialidades abandonaron temporalmente la frontera para unirse a la Confederación Indígena de Calfucurá, al retornar al servicio de las defensas fronterizas a finales de la década de 1850, estas prácticas de interrelación -afianzadas desde la década de 1830- se sumaron a los procesos de mestizaje desarrollados en la etapa posterior. Los caciques de estas tribus amigas actuaban como nexo entre el mundo criollo y el indígena y esa posibilidad de manejo y articulación entre dos culturas distintas, a diferencia del resto de los integrantes de la tribu, les confería el rol de intermediarios con los demás actores de la frontera y la campaña. La actuación de los caciques como nexo entre las dos culturas les permitía tener relación directa con los principales actores fronterizos, tanto los del poder político central como los locales, es decir, comandantes de frontera, jueces de paz, estancieros y comerciantes. Este círculo de contactos privilegiados les proporcionaba el acceso a bienes y les daba la posibilidad de acumulación material a título personal, cuestión que no ocurría con el resto de la tribu. Estos últimos establecieron una relación de integración en la vida de frontera, que pasaba por el mestizaje, tanto biológico -con los sectores más bajos de la población rural- como a través de la inserción laboral en las actividades agropecuarias y por constituirse en importantes actores comerciales de la campaña ${ }^{12}$.

La concesión de tierras a estos grupos indígenas -en la década de 1860 y bajo el

10 Ratto, 2003, p. 194-196.

11 De Jong, 2003, p. 56.

12 Mandrini, 1997, p.30-32; Quijada, 2002, p.115-118. 
gobierno de Mitre- fue, junto con el Negocio Pacífico de Rosas, otro de los factores clave de las relaciones interétnicas. Era una política tendiente a incrementar el número de "indios amigos", por medio del otorgamiento de cargos militares, raciones y permisos de asentamiento en la frontera ${ }^{13}$. A raíz de la Guerra del Paraguay la frontera estaba desguarnecida y las tribus amigas eran prácticamente la única fuerza de defensa. De modo que en este período muchos caciques obtuvieron la concesión de las tierras que ocupaban, como contraparte por los servicios prestados al ejército ${ }^{14}$. La mayoría de estos grupos se mantuvieron fieles a las fuerzas provinciales y estables en sus asentamientos, sobre todo aquellos cuyos caciques manejaban adecuadamente las relaciones con las autoridades militares de la campaña.

Los conflictos en la frontera rara vez se habían presentado en términos de enfrentamientos interétnicos, sino que estos conflictos estaban marcados por las disputas políticas entre Buenos Aires y el resto de las provincias, en las cuales los indígenas aliados se acomodaban en uno u otro bando. Si la instalación de tribus amigas en la frontera había favorecido el desarrollo ganadero de las estancias a la vez que propiciaba una nueva forma de interacción con la población "blanca", con el corrimiento de la línea militar los indígenas ya no cumplían una función específica. Junto con la llegada del ferrocarril y la necesidad de incrementar las tierras agrícolas productivas, durante la década de 1870, su presencia contribuía a desvalorizar las tierras ${ }^{15}$. Para los "indios amigos", su situación de permanencia en la frontera se volvió inestable. Desde los poderes locales se alentaban los enfrentamientos entre grupos indígenas con la intención de despojarlos de sus tierras. Esas disputas por el poder político central y las estrategias de avance de la frontera, sobre todo con la materialización de la zanja de Alsina hacia 1877, llevaba a estas tribus a una situación desesperante.

Esta etapa se caracterizó por la crisis del lugar de intermediación ocupado por los caciques amigos. Estos ya no tenían igual posibilidad de negociación en un escenario en el cual los enfrentamientos con el Estado los ubicaban en franca desventaja. Se habían alterado las condiciones y modalidades de integración de los "indios amigos" en la frontera, por lo cual muchas tribus se vieron forzadas a abandonar sus antiguos espacios de asentamiento o a unirse a las fuerzas de la Confederación Indígena reorganizadas por Namuncurá luego de la muerte de su padre Calfucurá. Otros caciques optaron por estrategias de conciliación y de acentuación de gestos simbólicos de pertenencia a la sociedad "blanca". Esta imposibilidad de negociación, así como la reducción del margen de intermediación del cacique, provocó el cuestionamiento de la autoridad de los mismos sobre el resto de su gente y la consecuente fragmentación de las tribus ${ }^{16}$.

13 También deben tenerse en cuenta, entre otros factores, las derrotas militares -algunas sufridas por el propio Mitre- de mediados de la década de 1850 que evidenciaron la imposibilidad de someter por las armas a las tribus pampeanas.

14 De Jong, 2005.

15 De Jong, 2003, p. 70

16 De Jong, 2005. 
Anteriormente se hizo referencia a que un modo de fortalecer la organización institucional del gobierno de la provincia de Buenos Aires -luego de imponerse a la Confederación en la batalla de Pavón ( 1861 )-, fue mediante la definición de estrategias a seguir con los grupos indígenas que habían sido fieles al gobierno. Esta etapa se caracterizó por el otorgamiento de tierras en la zona de la frontera con la condición que estos grupos aliados participaran en la defensa de los fortines o en acciones similares ${ }^{17}$ (Figuras 2 y 3 ).

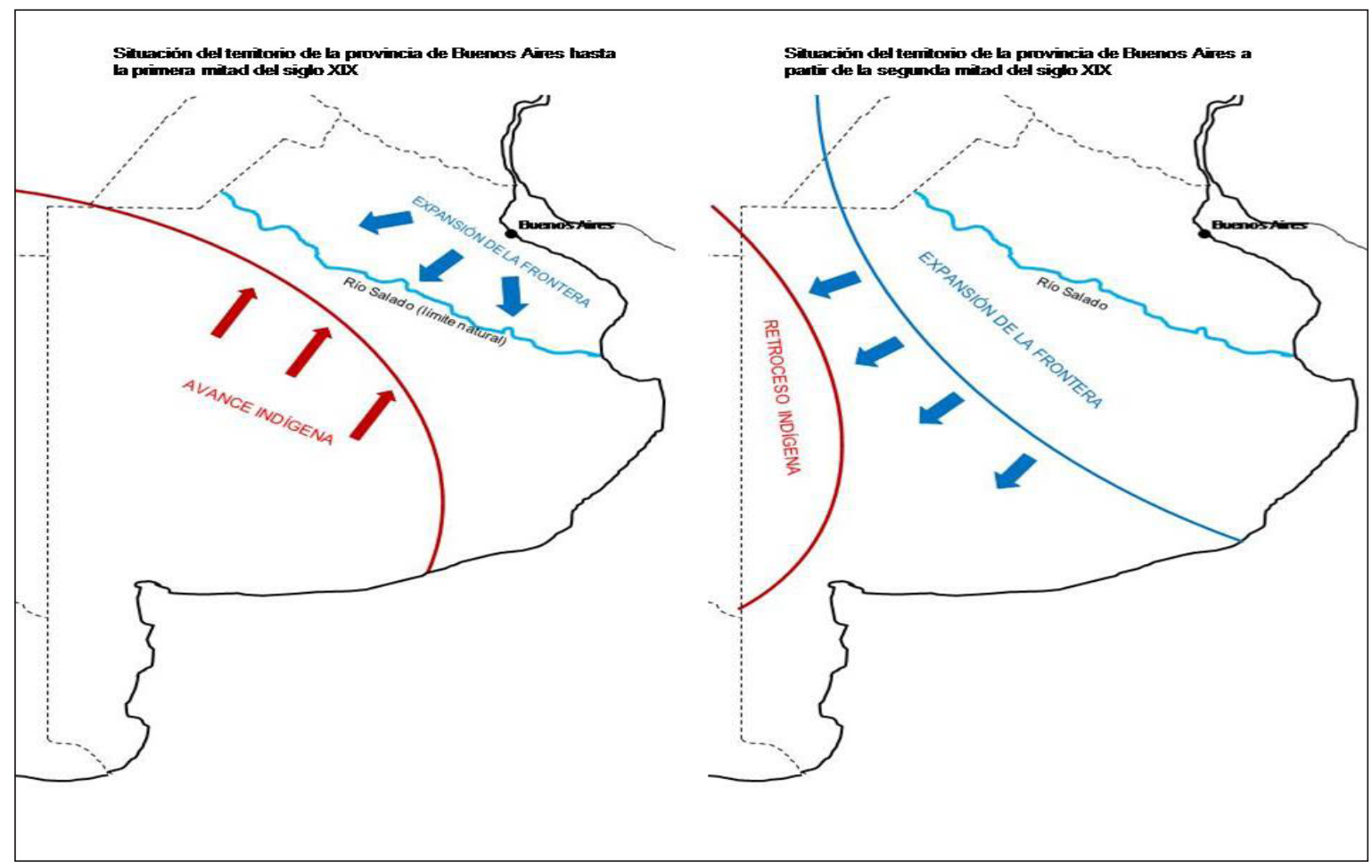

Figura 2. Esquemas de ocupación del territorio pampeano.

A: hasta la primera mitad del siglo XIX el control del Estado se limitaba a las proximidades del río Salado. B: luego de la segunda mitad del siglo XIX la frontera se expandió hacia el oeste, con el consecuente retroceso de la ocupación indígena.

Fuente: Elaboración propia.

\section{La tierra y la relación con los indígenas}

La idea de ocupar el territorio mediante la fundación de poblados pervivió como modelo de solución al problema agrario rioplatense en la primera mitad del siglo XIX. Este consenso se tradujo en una alternativa constante basada en la regularidad formal como instrumento técnico ${ }^{18}$. Cabe señalar que en la definición del modelo de ciudad no se impuso una forma específica sino que se propuso un conjunto de

17 Dos conceptos fundamentales y determinantes de las leyes de concesión (mal llamadas de donación) eran, por un lado, el establecimiento de destacamentos militares en la frontera y por otro, la preservación del trato pacífico con los "indios amigos". Ver La Tribu y las tierras de Coliqueo. Informe de la Comisión especial designada por el Poder Ejecutivo, Provincia de Buenos Aires, La Plata, 1940.

18 Aliata, 2006 
componentes que tendían a la aplicación de la trama ortogonal. Si bien no se definió un modelo de trazado para la ciudad pampeana, se estandarizó el uso de ciertos elementos normalizados como ejidos, plazas, calles, manzanas, etc., que eran la expresión de la regularidad buscada ${ }^{19}$. Pero la delineación regular de los trazados urbanos y rurales, así como la subdivisión de las parcelas en propiedad individual, se asumía implícitamente destinada a la población hispano-criolla. Los indígenas, mientras tanto, eran desplazados, aniquilados o subsumidos dentro del nuevo ordenamiento territorial regulador.

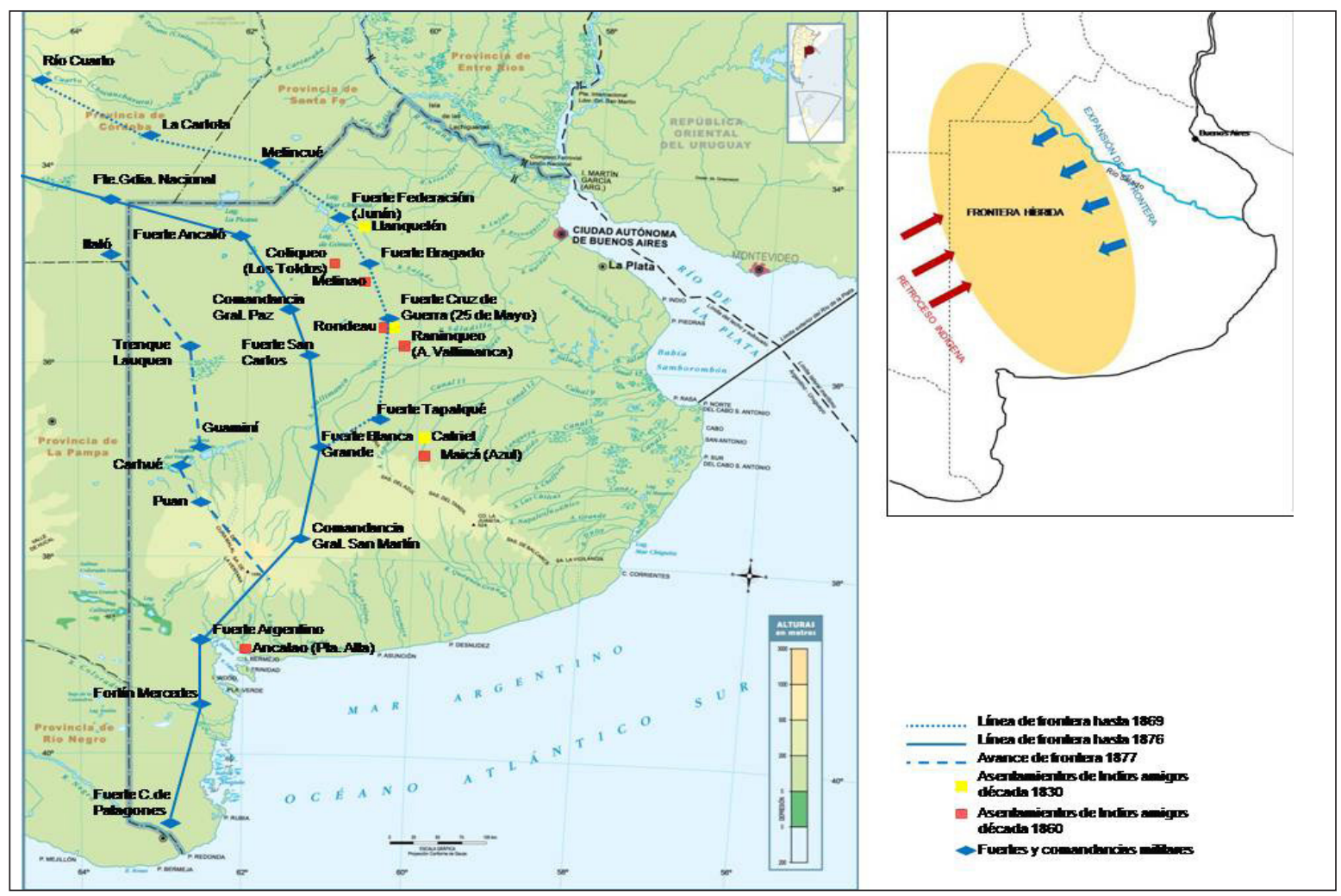

Figura 3. Esquema de asentamientos en la frontera.

Reconstrucción de asentamientos indígenas y fuertes militares.

Fuente: Elaboración propia.

El rol territorial otorgado a los indígenas en esta etapa de colonización era el de permanecer relegados o contenidos en áreas bajo control del Estado. Las campañas militares previas a las de 1879 habían acorralado -cuando no eliminado- a las poblaciones indígenas hacia la cordillera, de modo que la "frontera interna" se dio por finalizada en 1885 con la rendición del cacique Sayhueque en Neuquén.

Hasta ese momento, la existencia de las tribus en el territorio del nuevo Estado nacional fue tratada de muy diversas maneras desde la óptica oficial. Ese reconocimiento u ocultamiento de la presencia indígena se hizo notorio en las representa-

19 Pesoa, 2012. 
ciones cartográficas del territorio, producidas durante el siglo XIX.

Carla Lois ${ }^{20}$ señala que, a principios del siglo XIX, la cartografía de descripción territorial correspondía a la obra de extranjeros. Estos primeros trabajos realizados -en calidad de viajeros, naturalistas o eventuales cartógrafos- mostraron un panorama poco favorable en las instancias previas al emprendimiento de campañas militares de conquista, ya que en los mapas se reconocía explícitamente la presencia y el dominio indígena sobre gran parte del territorio federal. Estos trabajos representaban la mirada "extranjera" sobre el actual territorio argentino. Si bien muchos de estos personajes habían sido contratados o apoyados por los gobiernos de turno, hacia 1880 se los acusaba de haber producido trabajos viciados de errores. De allí en más, la cartografía pasó a depender de la esfera militar.

A partir de 1879, en coincidencia con la creación del Instituto Geográfico Argentino y en víspera de la "Campaña al Desierto" de Roca, se inició el periodo que marcó el quiebre de la cartografía como obra de extranjeros, hacia una cartografía oficial de impronta militar. El plano de Olascoaga de $1879^{21}$ eliminó detalles y explicaciones de los relevamientos realizados en operaciones exploratorias, omitiendo mencionar la existencia de tribus indígenas y su dominio sobre determinadas regiones, lo cual impedía tener un conocimiento cabal del territorio en cuestión. Las "áreas no exploradas", denominadas por los ingenieros militares, fueron excluidas por Olascoaga, quien prefirió dejar en el mapa el espacio en blanco. Todos los mapas militares de finales del siglo XIX se centraron en el relevamiento de las "fronteras interiores" y las posiciones que se avanzaban sobre el territorio antes dominado por los indígenas. Este cambio no solo fue en términos cartográficos sino que representaba la existencia de un conflicto por resolver en ese momento: qué hacer con los indígenas.

Esta necesidad de "invisibilización" se vio reflejada en las políticas de tierras destinadas al asentamiento de las tribus. Algunos autores proponen que no medidas sistematizadas. Es decir, plantean que no existió una continuidad en las acciones de radicación y entrega de tierras a los indígenas, aunque hubo una estrategia asimilacionista, que tendía a la "ciudadanización" de estos grupos y cuyo propósito era hacerlos "invisibles" dentro de la sociedad ${ }^{22}$. Pero esta ausencia de acciones unificadas no elimina la existencia de soluciones particulares en la radicación de diversos grupos indígenas. El caso de los asentamientos de "indios amigos" en la provincia de Buenos Aires será tratado más adelante, pero otros autores plantean la acción de políticas selectivas y no uniformes, a partir de la década de 1880, para la ocupación

20 Lois, 2006.

21 Título del plano de Olascoaga: "Plano del territorio de la Pampa y Río Negro y las once provincias chilenas que lo avencindan por el oeste. Comprende el trazo de la batida y exploración general hecha últimamente en el desierto hasta la ocupación definitiva y establecimiento de la línea militar del Río Negro y Neuquén por el Ejército Nacional a órdenes del Sr. Gral. D. Julio A. Roca. Construido en vista de planos, croquis parciales, itinerarios de los jefes de las divisiones y cuerpos espedicionarios (sic) de los ingenieros militares que los acompañaron y según exploraciones y estudios propios por el Tte. Cnel. Manuel J. Olascoaga, Jefe de la Oficina Topográfica Militar" Mapoteca Instituto Geográfico Nacional (IGN).

22 Quijada, 1999, p. 690. 
de la pampa y nor-patagonia ${ }^{23}$.

Antes de la campaña de Roca la política de tierras respecto de los indígenas se definía en el contexto de la legislación que regulaba el ordenamiento de las colonias agrícolas, aunque con una tendencia a diferenciarlos, ya que la idea de colonia se aplicaba a los contingentes de inmigrantes mientras que para los indígenas se reservaba la figura de las reducciones o misiones.

El primer antecedente de un plan de ocupación de la pampa y la patagonia, data de la presidencia de Mitre, en 1867, con la Ley nacional no 215 que dispuso el traslado de la frontera hasta los ríos Negro y Neuquén. Esta ley establecía que se les debía conceder a las tribus "todo lo que sea necesario para su existencia fija y pacífica" $\left(\right.$ art. $2^{\circ}$ ) y que la extensión de los territorios que se les otorgaran, ubicados entre la actual y la nueva línea de frontera, sería fijada "por convenios entre las tribus que se sometan voluntariamente y el Ejecutivo de la Nación" (art. $3^{\circ}$ ), mientras que todas aquellas tribus que se resistieran al "sometimiento pacífico" serían "arrojadas" por el ejército al sur de los ríos Negro y Neuquén (art. $4^{\circ}$ ). Básicamente la ley pretendía, por un lado, fijarlos a un territorio determinado y por otro, que pasaran a depender de la esfera estatal. De todas maneras, las dificultades entre Buenos Aires y los gobiernos provinciales, así como la guerra contra Paraguay, demoraron la ejecución de estos proyectos y recién en 1875, con Alsina, se encaró una política sistemática de avance sobre las tierras indígenas.

Con la ley de Inmigración y colonización -o Ley Avellaneda ( 1876)-, la política hacia estos grupos quedó integrada al plan colonizador. El capítulo III de la misma, Colonización, donaciones, venta y reserva de tierras- establecía que entre cada sección subdividida, se dejara una sin dividir, pero amojonada en las esquinas, con tres destinos posibles: la colonización por parte de empresas particulares; la reducción de "indios"; o el pastoreo (art.97). Estas secciones eran equivalentes a cuadrados de $20 \mathrm{~km}$ de lado, es decir 40.000 hectáreas. El artículo 100 de esta ley especificaba que “El Poder ejecutivo procurará por todos los medios posibles el establecimiento en las secciones, de las tribus indígenas, creando misiones para traerlas gradualmente a la vida civilizada, auxiliándolas en la forma que crea más conveniente, y estableciéndolas por familia en lotes de cien hectáreas". De esta manera se pretendía subsumir -o volver invisible- a la población indígena dentro de un orden territorial regular, obligándola a adoptar modelos de asentamiento que no respetaban su tradición cultural comunitaria.

Entre los deberes y atribuciones de los gobernadores en los Territorios Nacionales, la ley de 1884 dispuso la creación de misiones para el establecimiento de las tribus indígenas, siguiendo el espíritu "civilizatorio" de la ley de colonización de $1876^{24}$.

23 Briones y Delrio, 2002.

24 Ley No 1532, División de los Territorios Nacionales (1884), Art. 7: El Gobernador tendrá los deberes y atribuciones siguientes: inc. $11^{\circ}$ : Procurará el establecimiento, en las secciones de su dependencia, de las tribus indígenas que morasen en el territorio de la Gobernación, creando con autorización del Poder Ejecutivo las misiones que sean necesarias para traerlos gradualmente a la 
Luego de 1880 se identifican distintas formas de radicación, que representan una multiplicidad de soluciones en la política de radicación de grupos nativos, es decir, respuestas estatales puntuales a casos particulares de asentamiento. Briones y Delrio $^{25}$ diferencian varios tipos de soluciones colectivas. Por un lado, la figura de las reducciones, que buscaban "civilizar" a estos grupos; y las colonias pastoriles en las cuales se asentaban los grupos más adaptados a la vida criolla. Ambas estrategias se inscribían en la idea de un disciplinamiento previo a la "invisibilización" o "argentinización" del elemento indígena. Por otro lado, se hallaban las soluciones aplicadas por leyes especiales del Congreso a grandes caciques rebeldes como Sayhueque y Namuncurá y a jefes de menor rango, a los cuales les otorgaron permisos precarios en tierras fiscales. Estas soluciones, que en principio daban una respuesta a grupos comunitarios, empezaron a plantear conflictos entre la idea de comunidad y la de propiedad privada. En los casos de ocupación precaria, es decir, cuando no se tenía título de propiedad, hubo una tendencia al reconocimiento de la posesión de la tierra a la tribu en su conjunto, mientras que en los proyectos de colonias se buscaba concretar la propiedad individual. A medida que aumentaba la población de estos grupos, la tierra se volvía cada vez más escasa, lo que provocaba la expulsión de sus integrantes, desmembrando la concepción de comunidad.

Este tipo de políticas llevadas adelante con las poblaciones indígenas hacia finales del siglo XIX habían logrado segmentar grupos incluso antes de las campañas militares de 1878-79, obligándolos a reagruparse en áreas marginales y poco productivas. Desde principios de la década de 1870 se había iniciado el desmembramiento de los ranqueles por medio de las reducciones franciscanas ubicadas al sur de Córdoba y San Luis. Claudia Salomón Tarquini ${ }^{26}$ señala que de estos asentamientos provendría, por medio de traslados forzados, parte de la población de Victoria y General Acha (1882), las dos primeras localidades del Territorio Nacional de La Pampa (Figura 4).

En 1899 los ranqueles recibieron tierras en la colonia Emilio Mitre, también en La Pampa, mediante la ley 1501, que establecía la concesión de tierras específicamente para ganadería, es decir, no como reserva ni colonia indígena. El colono tenía la obligación de "poblar" las tierras con ganado y cultivos durante cinco años y luego de ese lapso iban a ser entregados los títulos de propiedad. La colonia tenía una superficie total de 80.000 hectáreas, en forma de $\mathrm{H}$, compuesta por 8 secciones cuadradas de $10 \mathrm{~km}$ de lado cada una, siguiendo la subdivisión propuesta por la ley No 947 de 1878. Cada una de estas secciones estaba subdividida en 16 lotes de 625 ha., de los cuales 108 lotes fueron entregados a familias, 8 lotes se dejaron como reserva para el pueblo, de acuerdo a lo estipulado por el art. $4^{\circ}$ de la ley 1501 y 12 lotes quedaron sin adjudicar. La superficie de los lotes, 625 hectáreas en tierras infértiles, resultaba insuficiente para la producción, pero algunas familias lograron organizar-

vida civilizada.

25 Briones y Delrio, 2002.

26 Salomón Tarquini, 2010. 
se $y$, sin alambrar los campos, compartieron pasturas y aguadas, aunque legalmente las tierras estuvieran registradas como cedidas a jefes de familias nucleares ${ }^{27}$.

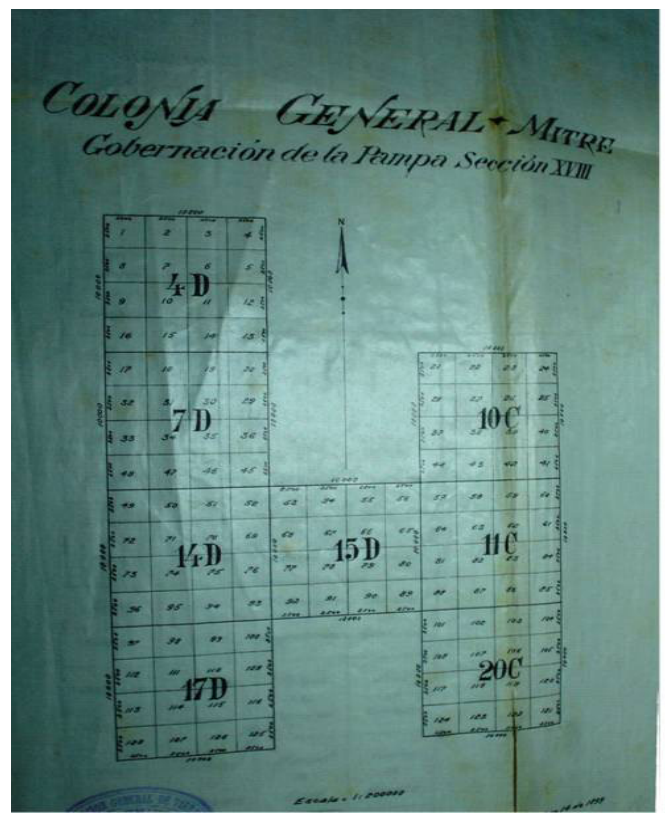

Figura 4. Subdivisión regular de la Colonia Mitre.

Fuente: Expte N 518, sección XVIII, Dirección General de Catastro de la Provincia de La Pampa, en Salomón Tarquini, 2010.

Este tipo de solución para la colonización indígena no resultó muy beneficioso para los grupos involucrados, que a la larga tuvieron dificultades para demostrar el poblamiento efectivo de las tierras y eso se tradujo en la imposibilidad de obtención de los títulos de propiedad.

De todas maneras estas políticas de tierras, ensayadas con diversas soluciones, no implicaron la desaparición de los grupos indígenas del territorio controlado por el Estado. En medio de las acciones estatales rapsódicas en materia de asentamientos poblacionales para las tribus, algunas experiencias puntuales durante la década de 1860 en la provincia de Buenos Aires resultaron "exitosas" teniendo en cuenta el clima convulsionado y de constante transformación vivido por las poblaciones de frontera.

\section{El Estado bonaerense y la concesión de tierras a los "indios amigos"}

A diferencia del periodo rosista -durante el cual no se entregaron tierras en propiedad a las tribus-, después de 1852 el Estado provincial debió contemplar la existencia de asentamientos, tanto rurales como urbanos, ocupados exclusivamente por indígenas. Dentro del contexto de organización territorial impulsado por el nuevo orden institucional luego de Caseros, se hicieron frecuentes las cesiones de tierras en propiedad a los "indios amigos". Los tratados de paz acordados con estas parcia27 Salomón Tarquini, 2010. 
lidades ${ }^{28}$ marcaron la reorientación de la política bonaerense hacia los indígenas, una política que estaba enfocada en el avance de la frontera y en las expediciones ofensivas a las tolderías indígenas en pie de guerra.

Durante la década de 1860, muchas tribus -que habían cumplido servicio militar en la frontera como "Indios Amigos" con el gobierno de Rosas- se asentaron en las tierras fronterizas. Fue el caso de los caciques borogas Mariano, Martín y Francisco Rondeau, en la zona de 25 de Mayo; las tribus de Coliqueo, José María Raylef y Ramón Melinao en Bragado; la tribu de Andrés Ancalao en Bahía Blanca y cerca de él, los caciques Cañumil y Linares en Patagones; el asentamiento del cacique pampa-tehuelche Mariano Maycá en la zona de Tandil; el cacique boroga Pedro Guayquil en el actual partido de Olavarría; las tribus del cacique pampa Mariano Quentrel en Tapalqué y las de Manuel Grande en la zona de Azul; el cacique pampa Pichihuincá en la zona de Azul, en las tierras de Villa Fidelidad ${ }^{29}$.

Durante la guerra con el Paraguay ( 1865) las fronteras habían quedado desguarnecidas militarmente y las tribus amigas actuaron casi como única defensa. En este estado de cosas, varios caciques solicitaron la concesión de las tierras que ocupaban, como compensación por los servicios prestados, ya que muchos de ellos tenían una continuidad de más de treinta años en las fuerzas militares de la frontera ${ }^{30}$. De manera que durante la década de 1860 el Congreso de la Provincia de Buenos Aires otorgó la propiedad comunal de las tierras a muchas tribus emparentadas de origen boroga como las de Rondeau, en 25 de Mayo, Coliqueo, Railef y Melinao, por los alrededores de Bragado, Raninqueo en Bolívar, Ancalao cerca de Bahía Blanca y al cacique pampa Maicá en Azul' ${ }^{31}$.

Pero todas las tribus no corrieron la misma suerte al momento de solicitar tierras al gobierno. La distribución de las mismas fue diferente según la zona de la provincia, ya que mientras en el centro-oeste se entregaron títulos formales, no ocurrió lo mismo con las tribus de la frontera sur. A las tribus catrieleras de Tapalqué, el gobierno les reconoció derechos sobre unas 54.000 hectáreas al oeste del arroyo Tapalqué, reconocimiento que luego fue dejado sin efecto, ya que el deslinde proyectado inicialmente nunca se concretó, pero al momento de la pacificación este reconocimiento de derechos sobre las tierras jugó un rol muy importante. Esta disparidad en la distribución de tierras entre una zona y otra puede atribuirse a que cada jurisdicción de frontera representaba un contexto distinto, ya fuera por el volumen de población indígena presente y sus vínculos con los sectores indígenas no alineados con el Estado, como también por las relaciones del poder local, es decir, de los funcionarios militares de frontera con el poder político central, generando redes

28 Tratados de paz entre el gobierno bonaerense y Catriel (1856), entre el gobierno nacional y Yanquetruz (1857) y Sayhueque (1863), tratados de paz con el cacique Mariano Rosas (1865) y Calfucurá (1866). En Hernández, 2003, p.92.

29 De Jong, 2005.

30 Ancalao, Rondeau, Collinao y Llanquelén se habían instalado en la línea de frontera durante el período rosista.

31 De Jong, 2003, p.55. 
clientelares favorecidas por el contexto de la frontera ${ }^{32}$.

\section{La propiedad colectiva de los asentamientos "amigos" en la frontera}

Es necesario destacar en este punto la importancia de la cuestión sobre las tierras concedidas a los indígenas durante la organización territorial y el peso que esto significaba para la política provincial, al punto que esta materia era objeto de debate en la legislatura bonaerense. Los diarios de sesiones ponen de manifiesto las controversias generadas en el seno del cuerpo legislativo no sólo en lo relacionado a discusiones formales sino a posturas ideológicas que demostraban una clara división de opiniones a favor y en contra tanto de la entrega de tierras, en particular, como de la existencia de los pueblos indígenas, en general. Pero en medio de estas discusiones subyacía una problemática que en definitiva se había convertido en cuestión de Estado y requería de soluciones a la altura de las circunstancias.

Si nos atenemos a la cronología, la tribu del cacique pampa Maycá fue la primera parcialidad que recibió tierras en el partido de Azul en 1856, en forma casi simultánea con las negociaciones que finalizaron en el Tratado de paz firmado entre el gobierno provincial y los caciques Catriel y Cachul. El gobierno de Buenos Aires, representado por el coronel Escalada, compró a la corporación municipal de Azul una extensión de tierra lindante al pueblo, que fue distribuida en cien solares, principalmente entre los integrantes de la tribu de Maycá ${ }^{33}$. Las particularidades de este otorgamiento de tierras fueron su localización en un área urbana, es decir, dentro de la traza del pueblo y la entrega de solares en propiedad individual -a diferencia del resto de las concesiones- a todos aquellos "indios amigos" que decidieran asentarse de forma permanente. Esto permitió la conformación de una villa urbana denominada "Villa Fidelidad" 34 , cuya modalidad en la adjudicación de los solares pudo estar vinculada a procesos de mestizaje cultural y de incorporación de grupos indígenas a las pautas de la organización estatal, ya que durante las incursiones a la frontera bonaerense, comandadas por Calfucurá en 1854 y 1855, la tribu de Maycá apoyó al gobierno porteño, incluso oponiéndose a los caciques principales Catriel y Cachul ${ }^{35}$.

La Villa Fidelidad se ubicó al oeste del arroyo Azul en un área cuadrangular de aproximadamente 500 metros de lado. Su estructura de plaza central y amanzanamiento circundante, se definió a partir de una grilla regular de manzanas -de unos 90 metros de lado- y calles intermedias. Siguiendo la disposición de la trama del pueblo de Azul, la villa también adoptó la orientación a medio rumbo, en sentido noroeste-sudeste. Cada manzana fue dividida en cuatro solares de aproximadamen-

32 Lanteri y Pedrota, 2009.

33 El terreno fue dividido en 100 solares de 50 varas $(1$ vara $=0.8666 \mathrm{~m})$ de frente por 50 de fondo, de los cuales 48 fueron repartidos entre la tribu de Maycá pero también a otros pertenecientes a las parcialidades de Catriel, Cachul y Manuel Grande. En De Jong et al, 2009, p. 17.

34 Actualmente el barrio Villa Fidelidad forma parte del ejido de la ciudad de Azul. Fuente: Pedrotta y Lanteri, 2010, p.71.

35 De Jong et al, 2009, p. 22; Lanteri y Pedrota, 2009. 
te dos mil metros cuadrados cada uno ( 50 x 50 varas). Los lotes fueron numerados de manera un tanto desordenada, aunque se puede establecer una lectura más o menos concéntrica, que se inicia en el lote sudeste ubicado frente a la plaza, con el número 1 , y siguiendo el sentido inverso a las agujas del reloj, se numeraron el resto de los lotes hasta llegar al último, en el extremo oeste de la villa ${ }^{36}$ (Figuras 5 y 6).
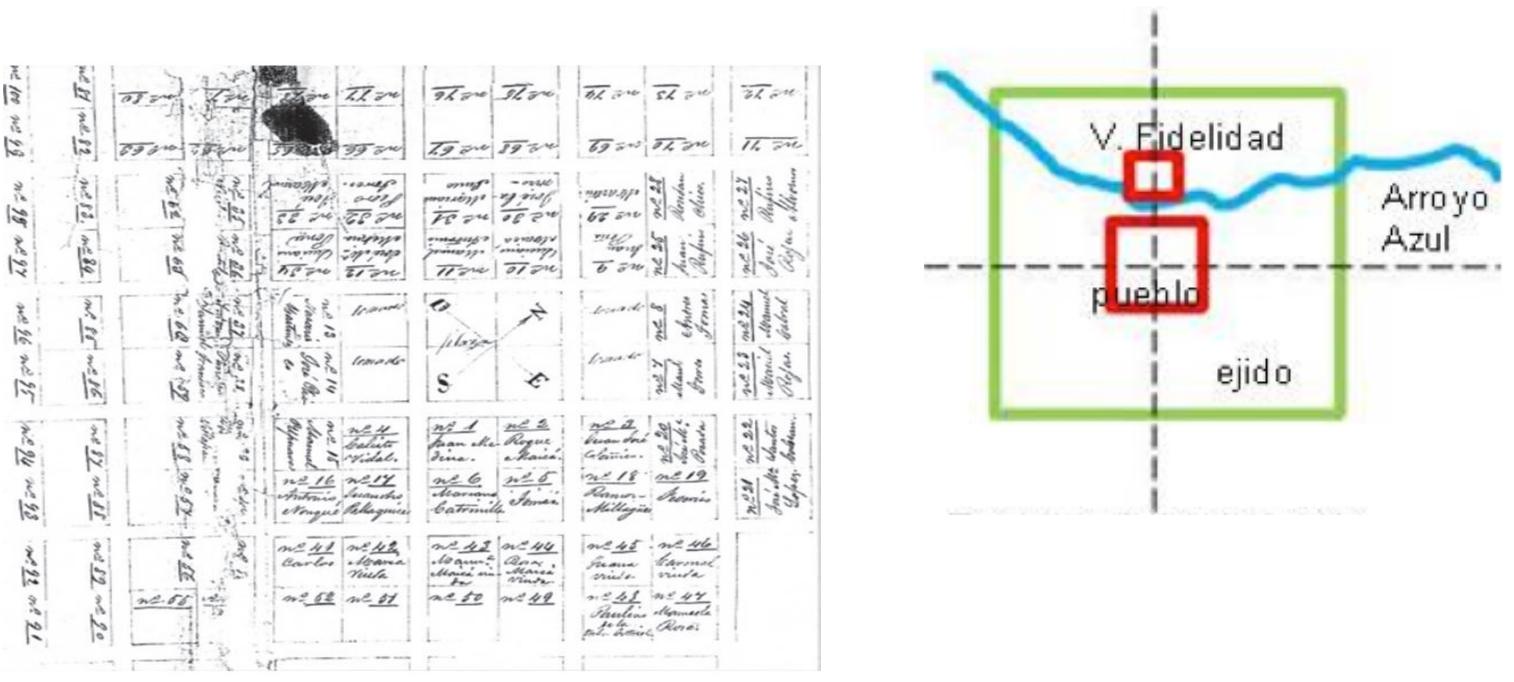

Figura 5. Plano y Esquema: Villa Fidelidad

Izquierda: Plano de Villa Fidelidad inscripto en un trazado ortogonal (1856). Derecha: Esquema de implantación de la villa respecto del pueblo y del arroyo Azul.

Fuentes: Lanteri y Pedrota, 2009 /Elaboración propia.

El resto de las concesiones de tierras a otras tribus llevadas a cabo durante la década de 1860 tuvieron características diferentes a la de Villa Fidelidad. Por un lado, compartían la figura legal por la cual la propiedad correspondía al cacique y su tribu, es decir, a toda la comunidad sin contemplar subdivisiones individuales entre sus integrantes, por considerar esta práctica contraria al modo de vida comunitario de la tribu. A esto se sumaba la imposibilidad de enajenar las tierras -previa autorización del poder Ejecutivo- antes de transcurridos diez años de ocupación efectiva. Según se desprende de los debates legislativos, este impedimento se fundaba en una cuestión más bien "tutelar" del gobierno hacia las tribus, por considerarlas "gente incauta":

"Que esa propiedad pase enteramente a ellos, pero que mientras esta propiedad no haya sido perfectamente esplotada por esa tribu, no pueda desprenderse sin que el gobierno comprenda con qué objeto; autorizando entonces la enagenacion: no sea que por cualquier accidente puedan ser sorprendidos, y que entonces esa

36 Plano de Villa Fidelidad (1856). Museo y Archivo Histórico Enrique Squirru de Azul (BA), en Pedrotta y Lanteri, 2010, p.65. 
anegación, sin un motivo digno y justo venga a convertirse en abuso de la misma concesión de la Lejislatura" ${ }^{37}$.

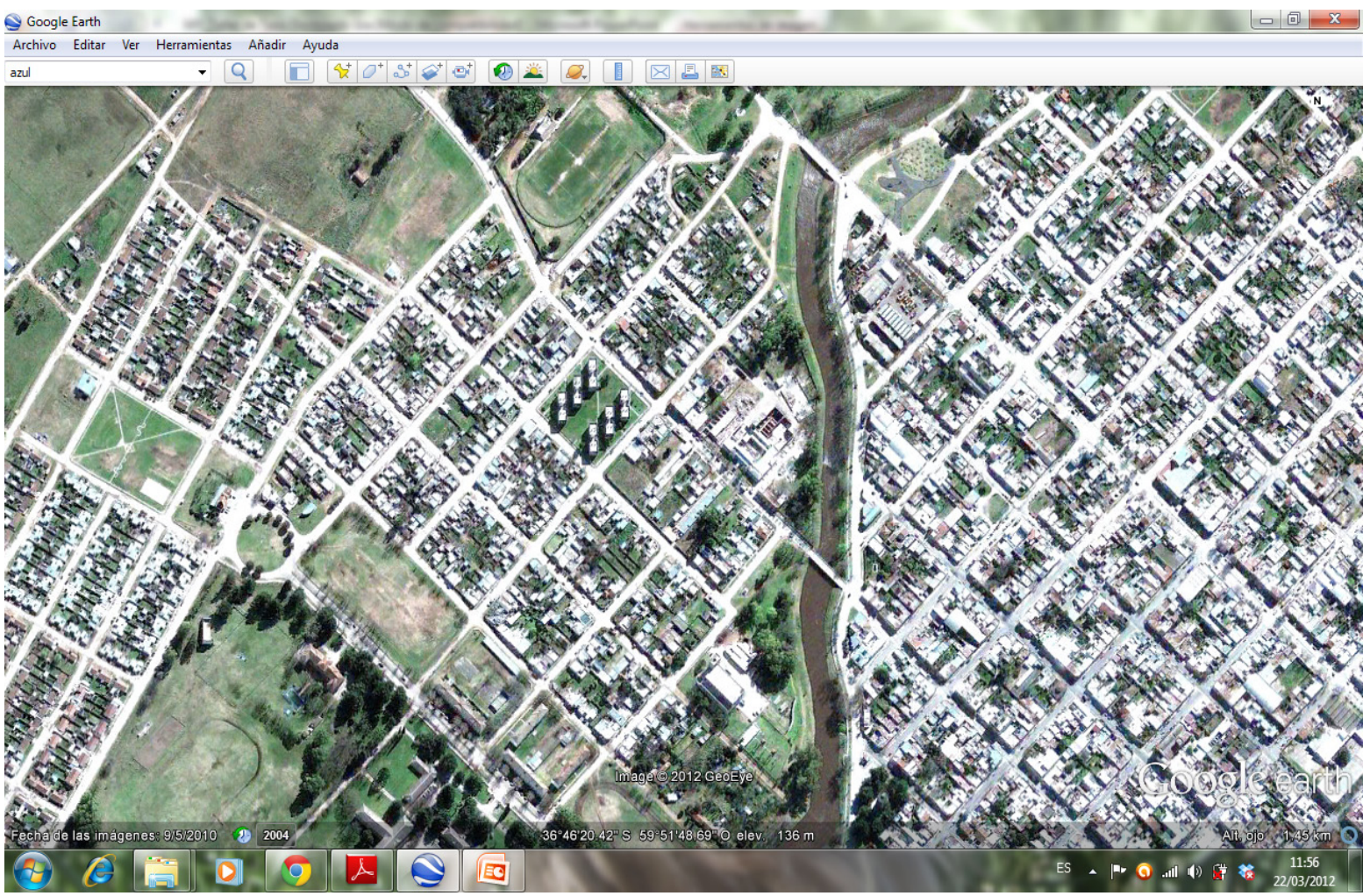

Figura 6. Actual barrio Villa Fidelidad en torno a una plaza central en Azul, provincia de Buenos Aires.

Fuente: Google Earth

Otra característica de estas concesiones era la localización de las tierras en zonas rurales de la frontera noroeste y sur de la provincia de Buenos Aires, donde se estaba consolidando la línea de defensa a base de comandancias y fortines apoyados por las "tribus amigas":

“(...) es muy laudable que todas estas tribus desde la concesión que se hizo a la de Melinao hace dos años, vayan tomando afición a la propiedad territorial. Este es el primer paso que se dá para la civilización de esos individuos. Aunque por desgracia todavía salvajes, es nuestra misión principal civilizarlos y utilizarlos ¿Quién puede tener mejor derecho a la tierra que estos naturales, que desde las remotas generaciones han sido siempre los dueños de ella?"38

Hasta el momento los documentos consultados permiten afirmar que la primera concesión de tierras a "tribus amigas", bajo las características comunitarias

37 Cámara de Senadores de la Provincia de Buenos Aires, Diario de Sesiones, Sesión del 12 de septiembre de 1865 sobre la solicitud de tierras del cacique Ancalao, p.109.

38 Cámara de Senadores de la Provincia de Buenos Aires, Diario de Sesiones, Sesión del 11 de octubre de 1866, p. 69. 
antes mencionadas, fue la realizada en 1863 al cacique Melinao y su tribu, por la cual se les entregó la propiedad de dos leguas cuadradas (aproximadamente 5.400 hectáreas) de las tierras que ocupaban en el partido de Bragado ${ }^{39}$. De acuerdo a los datos obtenidos en la división de Geodesia, estas tierras pertenecientes a Don Pedro Melinao y otros, ubicadas en la Estación Olascoaga del Ferrocarril Central del Oeste (FCO), fueron mensuradas y divididas en 1903 y estas subdivisiones modificadas en $1906^{40}$. La mayor de las parcelas, atravesada en su totalidad por una extensión de la laguna Barrancosa, correspondió a Pedro Melinao mientras que el resto se repartió de manera regular entre otros integrantes y descendientes de la tribu original. Todos los terrenos tienen formas cuadrangulares o de secciones poligonales regulares, inscriptas en un sistema de ejes cartesianos (Figura 7).

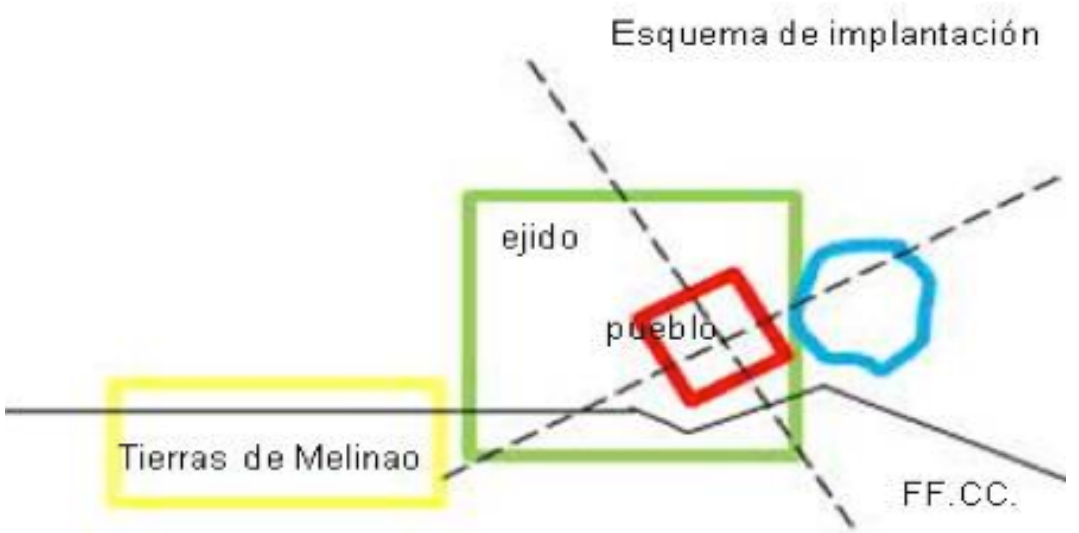

Figura 7. Esquema de implantación. Tierras de Melinao.

Fuente: Elaboración propia.

Si bien la mensura se realizó más de cuarenta años después del asentamiento de este grupo en la zona -y es probable que durante ese lapso haya habido un uso comunitario de la tierra-, debemos resaltar el hecho de que al cacique se le reservara el único lote con mayor extensión ( 618 ha) y con acceso al agua en toda su superficie. El resto de los lotes tienen un promedio aproximado de 40 ha y algunos se ven beneficiados por la presencia de espejos de agua menores, a veces compartidos entre dos terrenos y a veces acaparados por un solo propietario, aunque esta posibilidad de acceso al agua no se repitió en la mayoría de los lotes. Este hecho avala la teoría del rol del cacique como nodo informático ${ }^{41}$ y su situación de privilegio al momento de negociar el acceso a bienes, con la consecuente obtención de una ventaja respecto del resto de la tribu (Figura 8).

39 La Tribu y las tierras de Coliqueo. Informe de la Comisión...op., cit., p. 416; Provincia de Buenos Aires, Ley no 392, Concesión de tierras públicas en Bragado, al cacique Melinao, 9/9/1863.

40 Provincia de Buenos Aires, Dirección de Geodesia y Catastro, Duplicados de Mensura № 78 (1903) y No 100 (1906) del Partido de Bragado.

41 Bechis, 1992, p.85. 
En 1866 el poder legislativo provincial autorizó a escriturar la propiedad de dos leguas que el cacique Ancalao y su tribu ocupaban ${ }^{42}$ cerca de Punta Alta, en Bahía Blanca, señalando que: "Ni el citado Cacique ni su tribu, podrán enajenar ni el todo ni parte de dichas tierras, hasta después de transcurridos diez años desde que se otorgue el respectivo titulo de propiedad; y esto, previa autorización del Gobierno de la Provincia" ${ }^{\prime 3}$. El terreno, de unas 2.200 hectáreas aproximadamente, equivalía a una suerte de estancia, tenía su cabecera frente a la costa de la bahía y hasta 1890 figuraba a nombre de Francisco Ancalao ${ }^{44}$.

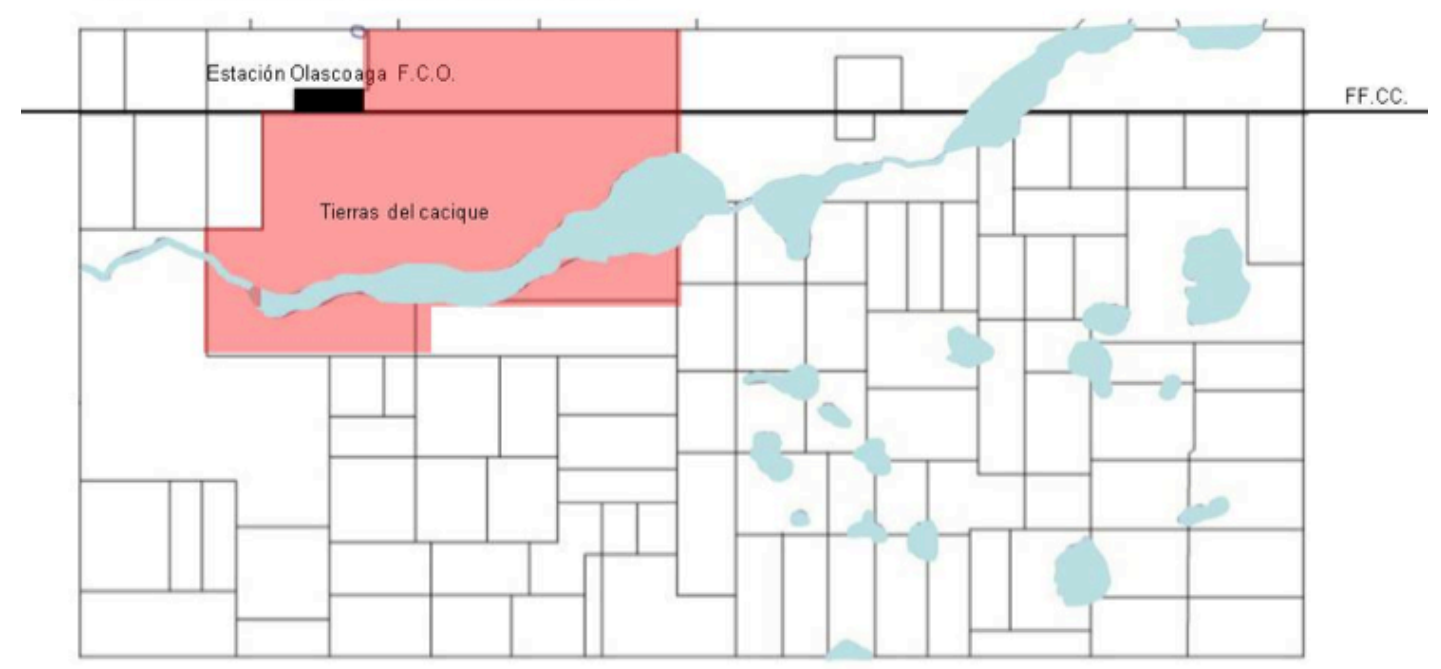

Figura 8. Reconstrucción de la subdivisión interna de las tierras de Melinao.

Las tierras de mayor superficie, resaltadas en color, corresponden al cacique. Las parcelas menores corresponden al resto de la tribu. Reconstrucción en base a la Mensura de 1903, Archivo Histórico de Geodesia. Fuente: Elaboración propia.

En la misma sesión se aprobó el proyecto de ley por el cual se acordaba la concesión de cuatro leguas de tierra (aproximadamente 10.800 hectáreas) a los capitanejos Martín, Francisco y Manuel Rondeau, en el actual partido de 25 de Mayo. Esta ley incluía el mismo impedimento para enajenar que en el caso de Ancalao y Melinao y una modificación introducida por el Senado en lo referente a la localización de las tierras. El proyecto proveniente de Diputados decía que los terrenos concedidos eran aquellos que la tribu estaba ocupando y que se preferían éstos "a cualquier otro que no tenga legitimo derecho reconocido", es decir, que se hacía hincapié en la obtención de las tierras que la tribu poblaba de manera efectiva. Pero en el proyecto

42 En el Registro Gráfico de 1864 figuran, sin deslindar, las tierras ocupadas por Ancalao en esa zona.

43 Cámara de Senadores de la Provincia de Buenos Aires, Diario de Sesiones, Sesión del 11 de octubre de 1866 , Art. $2^{\circ}$ del proyecto sancionado por el Senado y la Cámara de Representantes, pp.67 y 68; Provincia de Buenos Aires, Ley n ${ }^{\circ}$ 476, Concesión de tierras al cacique Ancalao y su tribu, $12 / 10 / 1866$.

44 Provincia de Buenos Aires, Dirección de Geodesia y Catastro, Duplicado de Mensura No 27 (1866) del Partido de Bahía Blanca. No se han encontrado subdivisiones posteriores que dieran señales de la existencia de la tribu. 
del Senado se introdujo la posibilidad de que la propiedad no sólo fuera del lugar donde estaban asentados, sino "donde no ofrezca inconveniente su ubicación", en un modo de evitar conflictos por derechos de propiedad adquiridos ${ }^{45}$. En 1867 se promulgó la ley de concesión ${ }^{46}$ a los tres capitanejos mencionados, pero ese mismo año Francisco Rondeau solicitaba al gobierno, por medio de un apoderado, la venta de media legua cuadrada que le subarrendaba a otro propietario. Lo hacía a título personal, es decir, ya no como cacique de una tribu sino como "Don Francisco Rondeau". Finalmente, el gobierno provincial le vendió a Francisco un octavo de legua, lo que refuerza la idea de la posición privilegiada de los caciques en este contexto de lealtades condicionadas ${ }^{47}$. Hasta el momento no se han encontrado subdivisiones o mensuras interiores de estas tierras. De hecho, en el Registro Gráfico de 1890 figuran unas dos leguas cuadradas a nombre de Francisco Rondeau en la actual localidad de Valdés, partido de 25 de Mayo, es decir, que ya no había ninguna referencia legal a la tribu (Figura 9).

45 Ibídem, p. 68 y 69.

46 Provincia de Buenos Aires, Ley n ${ }^{\circ}$ 512, Concesión de tierras a los capitanejos Martin, Francisco y Manuel Rondeau y su tribu, 1/10/1867.

47 Provincia de Buenos Aires, Dirección de Geodesia y Catastro, Duplicado de Mensura No 148 (1868) del Partido de 25 de Mayo. 

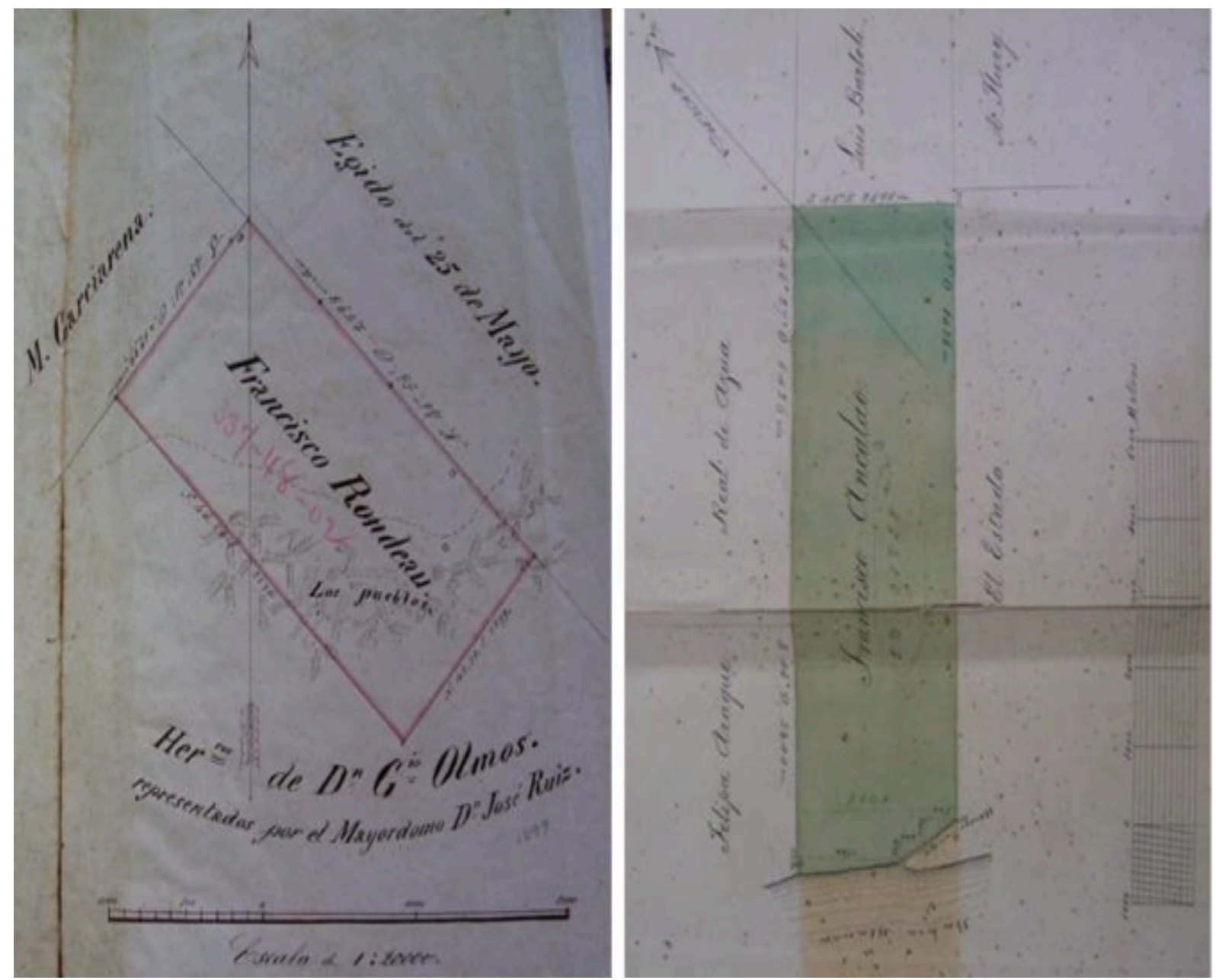

Figura 9. Mensuras de las tierras de Rondeau (1868) y Ancalao (1866). Fuente: Archivo Histórico de Geodesia.

Coliqueo fue otro de los caciques beneficiados por esta política de gobierno de la década de 1860 en la provincia de Buenos Aires. En 1862 había iniciado las gestiones para que le fueran concedidas dos leguas, también en la zona de Bragado y ratificado el pedido en 1863, aunque recién obtuvo la propiedad -de seis leguas cuadradas en total- entre 1866 y 1868. En 1866 se le concedió al cacique Ignacio Coliqueo y su tribu la propiedad de dos leguas cuadradas y en 1868 la de otras cuatro leguas cuadradas adicionales $^{48}$. En 1869 obtuvieron la escritura de las seis leguas totales ${ }^{49} \mathrm{y}$ en 1916 se practicó la mensura de la subdivisión interna de las tierras ${ }^{50}$.

Esta tribu de Los Toldos se manifiesta como un caso particular dentro del proceso de construcción del territorio de la frontera, ya que no se efectuó solamente a partir de aplicaciones planimétricas derivadas de normas jurídicas o de políticas y acciones oficiales, sino que también incorporó lógicas vinculadas a la topografía y a prácticas culturales autóctonas.

El factor hidrográfico resulta de fundamental importancia para comprender el

48 Leyes provinciales No 474 (2/10/1866) y No 552 (1/10/1868).

49 Archivo Histórico de Geodesia, Duplicado de mensura No 14, General Viamonte, 1869.

50 Archivo Histórico de Geodesia, Duplicado de mensura No 78, General Viamonte, 1916. 
modo de distribución territorial de la tribu, cuyo patrón de subdivisión guarda relación directa con la posibilidad de acceso al agua. Sobre el núcleo del asentamiento, en torno a la vivienda del cacique Ignacio, se encuentran las lagunas de la Azotea y Salamanca. Más afuera se halla la laguna Los Toldos, cuya mitad oeste se ubica dentro de las tierras de la tribu y hacia el sudoeste se encuentran las lagunas de Cotta, Morón, La Salada y el arroyo Morón (Figura 10).

Los lotes se recortan en torno a las lagunas o cursos de agua. Tomando como referencia la subdivisión de 1916, los espejos de agua son compartidos por dos o más lotes de tierra. Sobre la laguna Los Toldos, que es la de mayor superficie, se contabilizan más de diez lotes delineados de forma aproximadamente concéntrica. En la laguna de la Azotea, de menor superficie pero de mayor contenido simbólico para la tribu por su cercanía con el cementerio, las tierras se dividen en unos siete lotes con un esquema radial. Ocurre una situación de distribución similar con dos lagunas de gran superficie ubicadas al oeste de las tierras y con las lagunas menores y los cursos de agua, donde prima la necesidad de acceso al agua. Si bien se observan lotes de tierras que no comparten aguadas naturales, la mayoría logra un reparto bastante equitativo y los lotes sin acceso al agua al nivel de la superficie corresponden a las propiedades de mayor tamaño.

La ubicación de los principales integrantes de la tribu se concentraba en el extremo este del rectángulo de seis leguas cuadradas, en donde la presencia de lagunas era mayor. Controlando el perímetro de este asentamiento se localizaban cuatro puestos, tres de ellos sobre la avanzada de la frontera, al norte, al oeste y al sur y uno en la retaguardia, al este. Los puestos más alejados del reducto poblacional -el de Raninqueo al noroeste y el de Justo Coliqueo al sudoeste- dependían de la milicia de frontera. Estos puntos estratégicos pertenecían a integrantes de alto rango dentro de la tribu: Raninqueo era cacique segundo, es decir, el primero en la línea de sucesión del mando de la tribu, luego del cacique Ignacio; el otro puesto estaba a cargo de Justo Coliqueo, con el grado de sargento mayor e hijo del cacique principal. Por un lado, esto habla de jerarquías tribales pero también del régimen militar de la tribu. En su condición de destacamento de la frontera oeste de la provincia, tanto la tropa como los capitanejos eran destinados a otras compañías, en destacamentos distintos, incluso en otras tribus, siguiendo las alternativas de su rango militar y obedeciendo las disposiciones de las autoridades estatales. No hay que olvidar que Coliqueo tenía grado militar y cobraba un sueldo del Estado, así como sus capitanejos, además de la ayuda en alimentos y enseres proporcionada desde el gobierno provincial. 


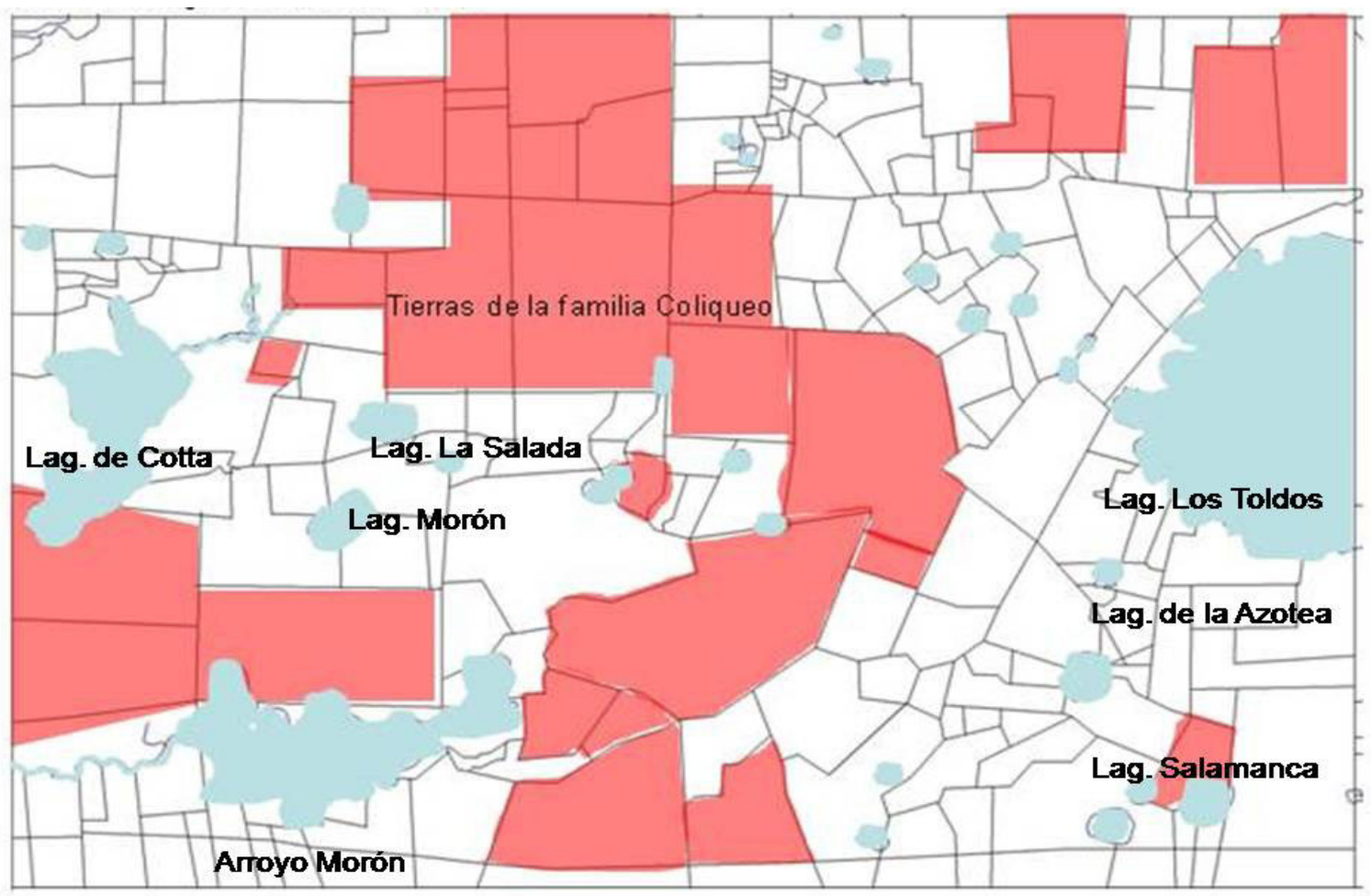

Figura 10. Subdivisión interna de las tierras de Coliqueo.

Las tierras de mayor superficie, resaltadas en color, corresponden al Cacique y a familiares directos. Las parcelas menores corresponden al resto de la tribu. Reconstrucción en base a la Mensura de 1916, Archivo Histórico de Geodesia.

Fuente: Elaboración propia.

Por su parte, el cacique Raninqueo -quien había sido cacique segundo de Coliqueo- se separó de la tribu luego que el gobierno provincial reconociera la propiedad de las tierras al cacique Coliqueo y su tribu, excluyéndolo de un título de propiedad individual. Debido a esto, finalmente la ley $\mathrm{n}^{\circ} 611$ de 1869 determinó la concesión de seis leguas cuadradas de campo (aproximadamente 16.000 hectáreas) “al Cacique Raninqueo y a los jefes de familia de su tribu", con iguales limitaciones que los casos anteriores para su enajenación en todo o en parte. La localización de las tierras sería "en el lugar en que actualmente acampan los agraciados en la frontera del oeste de la Provincia y a inmediaciones del Arroyo del Vallimanca". Esta ubicación estaba sujeta a "la conveniencia de la defensa de la frontera o derechos anteriores y legítimamente reconocidos", de lo contrario "se hará ella en los campos de los alrededores que se encuentren vacantes o que puedan obtenerse de sus poseedores, por cesiones gratuitas o por permuta"51 (Figuras 11 y 12 ).

51 Provincia de Buenos Aires, Ley no 61l, Concesión de tierras al cacique Raninqueo y su tribu, 19/10/1869. 


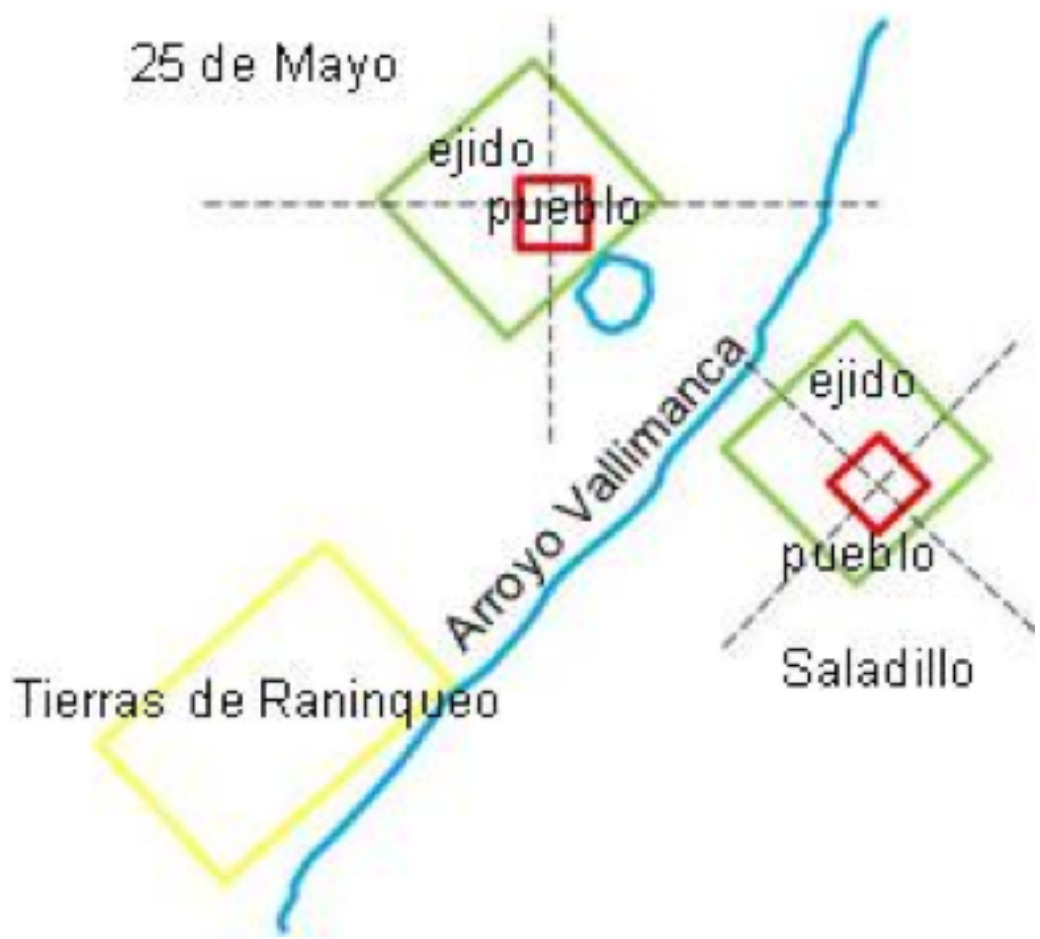

Figura 11. Esquema de implantación de las tierras de Raninqueo respecto del arroyo Vallimanca y de los pueblos de 25 de Mayo y Saladillo.

Fuente: Elaboración propia.

En 1870 se practicó la mensura y subdivisión de las tierras en un mismo acto, algo que no había ocurrido con las tierras concedidas al resto de las tribus amigas, excepto el caso de Villa Fidelidad en Azul. El gobierno de la provincia le dio instrucciones al agrimensor Octavio Pico acerca de la ubicación y la subdivisión de las seis leguas cuadradas para Raninqueo. Las tierras se dividieron en cuatro leguas cuadradas para el cacique principal Raninqueo y dos leguas cuadradas para el segundo cacique Tripailaf. La parte de Raninqueo se subdividió en una legua cuadrada para el cacique y tres leguas cuadradas distribuidas en dieciséis lotes para sus capitanejos. La parte de Tripailaf se subdividió en media legua cuadrada para él y una legua y media repartida en nueve lotes entre sus subalternos. Si bien no se establecía la pertenencia de cada lote, la división formaba figuras rectangulares que variaban su superficie ${ }^{52}$. Nuevamente, los caciques lograron mayores réditos que el resto de la tribu al momento de subdividir la tierra. La guerra territorial del siglo XIX generó cambios en el sistema social igualitario de las tribus, dando inicio a las relaciones de subordinación. Es decir que la estratificación social más marcada se vio justamente entre los grupos que tuvieron mayor contacto con la sociedad fronteriza, pudiendo diferenciar entre caciques -loncos-, caciques segundos, capitanejos e "indios de pelea" - conas- $^{53}$.

52 Provincia de Buenos Aires, Dirección de Geodesia y Catastro, Duplicado de Mensura No 11 (1870) del Partido de Bolívar.

53 Bengoa, 2008, p. 65 


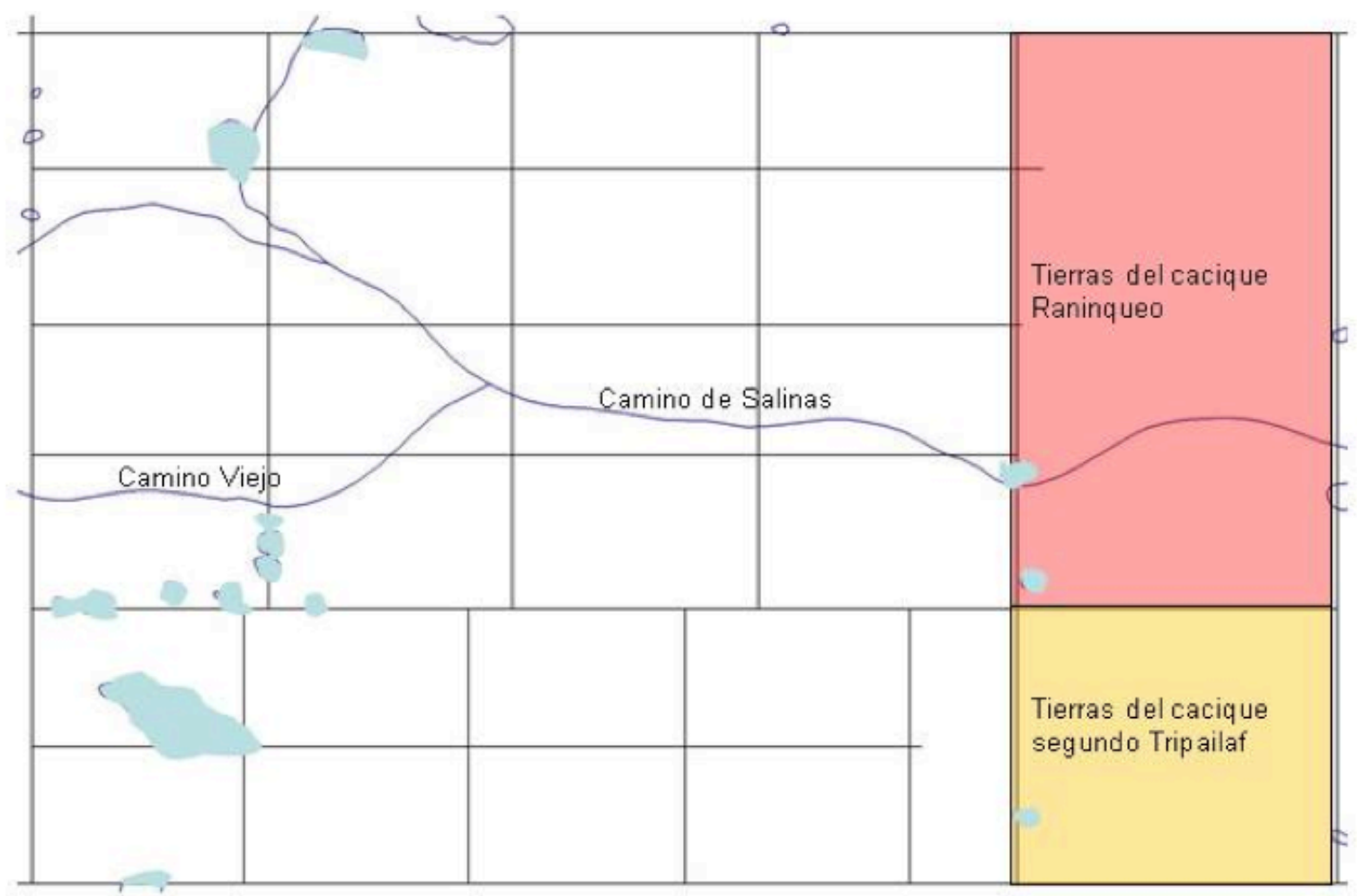

Figura 12. Reconstrucción de la subdivisión interna de las tierras de Raninqueo.

Las tierras de mayor superficie, resaltadas en color, corresponden al cacique principal y al cacique segundo. Las parcelas menores corresponden a los capitanejos de la tribu. Reconstrucción en base a la Mensura de 1870, Archivo Histórico de Geodesia.

Fuente: Elaboración propia.

En el caso de Raninqueo, sus lotes -además de una mayor superficie- tenían asegurada la existencia de aguadas naturales, algo que no ocurría con todos los lotes destinados a los capitanejos, ya que la mensura se ajustaba a una trama regular que no atendía a cuestiones topográficas o, como el caso de las suertes al norte del río Salado, no se planteaba la subdivisión en términos de asegurar el acceso al agua al mayor número de terrenos.

\section{Consideraciones finales}

En este estudio se trabajó una problemática espacial que involucra a los indígenas, al Estado y al territorio, entendiendo que todos ellos son producto de procesos históricos y el resultado de su mutua influencia. En el análisis se tuvo en cuenta: el entorno ambiental, las variables económicas, culturales y simbólicas relacionadas con las prácticas y tradiciones indígenas, su vinculación con los agentes o instituciones estatales con los que interactuaron y las condiciones político-militares de la 
frontera que dieron marco a dichos procesos. A partir de allí es posible señalar, por un lado, la comprensión acerca de las circunstancias que influyeron en los distintos modos de uso y otorgamiento de tierras a los grupos indígenas en la décadas de 1850-60, sea manteniendo la forma comunitaria tradicional o incorporando la figura de la propiedad privada. Por otro lado, se señala la indagación acerca de la figura de los caciques y las relaciones de jerarquía al interior de los grupos indígenas, la forma en que en ambas incidieron las relaciones con la sociedad criolla y sus distintas expresiones materiales plasmadas, por ejemplo, en el reparto diferencial de los lotes de terreno, sus dimensiones y disponibilidad de recursos hídricos.

Lo destacable de la concesión de tierras a "indios amigos" en el periodo estudiado fue la posesión comunitaria de las mismas, que se enlazaba en una trama de relaciones ancestrales e identitarias. La forma de asiento tradicional se basaba en una lógica interna de la comunidad que se articulaba con las actividades productivas y los vínculos económicos establecidos con la sociedad criolla, condicionada por la actividad ganadera. Tradicionalmente las poblaciones indígenas habían ocupado el territorio a partir de determinantes económicas y culturales. El establecimiento de las tolderías y campamentos podían tener una duración variable, casi siempre motivada por las actividades productivas que requerían desplazamiento en busca de condiciones naturales óptimas o dependiente de las jerarquías tribales, bajo el dominio de los cacicatos que gobernaban sectores territoriales étnicamente inter$\operatorname{conectados}^{54}$. Pero estos grupos indígenas siempre se habían resistido a la mensura de las tierras, rechazando cualquier subdivisión impuesta por cánones culturales que no se condecían con sus propias tradiciones en el uso y el valor simbólico de la tierra. Al respecto Alfredo Ebelot señalaba que "los indios sienten un tradicional sagrado horror por todo lo que significa mensura de tierras. Para ellos el agrimensor es objeto de un odio supersticioso que involucra a sus ayudantes, sus instrumentos y sus diabólicas operaciones (...) Los indios siempre los han visto preceder al colono y anunciar su llegada. Todo campo en donde el agrimensor aparece es campo perdido" 55 .

Es probable que estos grupos, vislumbrando un escenario futuro de despojo, no se opusieran a la mensura de sus tierras. Como vimos, las tierras que pertenecieron a Raninqueo, el cacique que compartía su asentamiento con la tribu de Coliqueo y que, -ante la legitimación de las seis leguas a este último- solicitó para él y su gente otra superficie similar, se subdividieron en 1870 al momento de la mensura. Esta subdivisión -a diferencia de la de Coliqueo- se realizó de forma regular, es decir, a partir de figuras inscriptas en el sistema de ejes cartesianos. Si bien no se trata

54 Raúl Mandrini, "Indios y fronteras en el área pampeana (siglos XVI-XIX). Balance y perspectivas", in Anuario IEHS VII (Tandil: UNICEN, 1992), 59-73.

55 Citado en Silvestri, 1999, p. 198. 
de una grilla o cuadrícula, las parcelas se ajustan a la configuración de polígonos regulares de cuatro lados, pero esa distribución se realizó respetando las jerarquías tribales, ya que los lotes mayores corresponden a los caciques y el resto se distribuyen entre los lugartenientes de cada uno. Lo mismo ocurrió con la subdivisión de las tierras de Melinao entre 1903 y 1906.

Vale decir que en la lógica de la aplicación de una grilla territorial para regular la subdivisión de las tierras estatales, en su paso a manos privadas, la mayoría de las poblaciones indígenas de la frontera se vio inmersa en esta tendencia formal dominante, aunque logrando adaptaciones vinculadas con la jerarquía y la estructura interna de las tribus.

El uso de cartografía y planimetría como fuentes documentales demostró que el relevamiento y conocimiento de la frontera fue una prioridad dentro del plan de expansión territorial del Estado. Aquí se entrecruzaron dos discusiones centrales, por un lado, el modo de implementar un sistema claro y ordenado para privatizar la tierra y por otro, qué hacer con los indígenas que la ocupaban. Durante el transcurso del siglo XIX la representación cartográfica del territorio se profesionalizó a partir del desarrollo de una serie de saberes específicos que pretendían alcanzar un conocimiento territorial más completo y garantizar así el control del Estado. El mapa sirvió no solo para "conocer" sino también para proyectar un plan de acción futura sobre un conflicto que se buscaba resolver.

En este trabajo, la utilización de las fuentes gráficas -en términos de organización del territorio y poblamiento- permitió hacer una reconstrucción planimétrica de los casos estudiados, y ello derivó en la producción de nuevos esquemas. Este ejercicio de "relectura" operado sobre la cartografía, así como el abordaje metodológico que articula el análisis de fuentes gráficas y escritas, busca contribuir a la actualización de la literatura sobre la frontera decimonónica en Argentina.

\section{Bibliografía}

ALIATA, Fernando. La ciudad regular: arquitectura, programas e instituciones en el Buenos Aires posrevolucionario: 1821-1835, Buenos Aires: Universidad Nacional de Quilmes, Prometeo. 2006.

ALIATA, Fernando. Las raíces del árbol de la libertad. El legado ilustrado en la fundación de pueblos en la pampa bonaerense durante el siglo XIX. Nuevo Mundo, Mundos Nuevos. Debates En línea. París: École des hautes études en sciences sociales, 23 de marzo de $2010<\mathrm{http} / /$ nuevomundo.revues.org/59222>. 23 de mayo de 2010. ISSN: 1626-0252

ALIATA, Fernando; LOYOLA, Omar. Transformaciones en el hábitat rural. Los planos topográficos de Chascomús, 1826 - 1854. Mundo Agrario. En línea. La Plata: Facultad de Humanidades y Ciencias de la Educación, Universidad Nacional de 
La Plata, 2010, Vol. 10 No 20 <http://www.memoria.fahce.unlp.edu.ar/art_revistas/ pr.4175/pr.4175.pdf>. 22 de julio de 2010. ISSN: 1515-5994

ALIATA, Fernando; CRICELLI, Susana; OBREGÓN, Rosana; YULN, Melina; ZWEIFEL Teresa, Del programa político a su materialización. Las alternativas a la colonización ejidal: Chivilcoy y las tierras de Coliqueo en la frontera bonaerense (18601890). In CICUTTI, Bibiana (comp.), La cartografía como objeto de cultura. Materiales para su discusión. Rosario: Nobuko- A\&P Ediciones, UNR, 2012, p. 179-210.

BECHIS, Martha. Instrumentos metodológicos para el estudio de las relaciones interétnicas en el periodo formativo y de consolidación de los estados nacionales. In HIDALGO, C. y TAMAGNO, L. (Comps.). Etnicidad e identidad. Buenos Aires: CEAL. 1992, p. 82-108.

BENGOA, José. Historia del pueblo mapuche, siglos XIX y XX. Santiago de Chile: LOM Ediciones. 2008.

BOCCARA, Guillaume. Fronteras, mestizaje y etnogénesis en las Américas. In MANDRINi, Raúl y PAZ, Carlos. Las fronteras hispanocriollas del mundo indigena latinoamericano en los siglos XVIII-XIX: un estudio comparativo. Neuquén: Universidad Nacional del Comahue. 2003, p. 63-108.

BRIONES, Claudia; DELRIO, Walter. Patria sí, colonias también. Estrategias diferenciales de radicación de indígenas en Pampa y Patagonia (1885-1900). In TERUEL, A.; LACARRIEU, M.; JEREZ Andes, Omar (Comps.). Fronteras, ciudades y Estados (Tomo I) Córdoba: Alción Editora. 2002, p. 45-78.

DE JONG, Ingrid. Historia, etnicidad y memoria: el proceso de conformación de la identidad indigena en la tribu amiga de Los Toldos (Provincia de Buenos Aires). Tesis doctoral dirigida por Lidia Nacuzzi. Buenos Aires: Universidad de Buenos Aires, Facultad de Filosofía y Letras, 2003.316 p.

DE JONG, Ingrid Identidades mestizadas, identidades escindidas: el proceso de etnogénesis entre los indios amigos de la frontera bonaerense (1860-1880). VI Congreso Internacional de Etnohistoria, Buenos Aires. 2005.

DE JONG, Ingrid Acuerdos y desacuerdos: política estatal e indígena en la frontera bonaerense (1856-1866). In MANDRINI, Raúl; ESCOBAR OHMSTEDE, Antonio; ORTELLI, Sara. Pueblos indigenas en América Latina, siglo XIX: sociedades en movimiento, Anuario del IEHS, Suplemento 1. Tandil: Instituto de Estudios Histórico Sociales, FCH/ UNCPA. 2007, p. 47-62.

DE JONG, Ingrid; LANTERI, Sol; PEDROTTA, Victoria; RATTO, Silvia. Políticas oficiales y territorialidad indígena en la frontera sur bonaerense durante el siglo XIX. El caso de Villa Fidelidad (1856-2009). Jornadas de Estudios Indigenas y Coloniales. Facultad de Humanidades y Ciencias sociales de la Universidad Nacional de Jujuy. 2009.

FISCHMAN, Gustavo; HERNÁNDEZ, Isabel. La ley y la Tierra. Historia de un despojo en la tribu mapuche de Los Toldos. Buenos Aires: CEAL. 1990.

GARAVAGLIA, J.; GAUTREAU, P. Mensurar la tierra, controlar el territorio: América 
Latina, siglos XVIII-XIV. Rosario: Prohistoria Ediciones, State Building in Latin America. 2011.

HERNÁNDEZ, Isabel et al. La Identidad Enmascarada. Los mapuche de Los Toldos. Buenos Aires: Eudeba. 1993.

HERNÁNDEZ, Isabel. Autonomía o ciudadanía incompleta: el pueblo mapuche en Chile y Argentina. Santiago de Chile: CEPAL, Naciones Unidas. 2003.

LANTERI, Sol; PEDROTTA, Victoria. Mojones de piedra y sangre en la pampa bonaerense. Estado, sociedad y territorio en la frontera sur durante la segunda mitad del siglo XIX. Estudios Trasandinos, Asociación Chileno-Argentina de Estudios Históricos e Integración Cultural, 2009, Vol. 15, p. 101-129.

LOIS, Carla. Técnica, política y deseo territorial en la cartografía oficial de la Argentina (1852-1941). Scripta Nova. Revista electrónica de geografía y ciencias sociales. En línea. Barcelona: Universidad de Barcelona, 2006, X, (218). <http://www.ub.es/ geocrit/sn/sn-218-52.htm>. 27 de octubre de 2010. ISSN: 1138-9788.

LÓPEZ OSORNIO, Mario A. Viviendas en la pampa. Buenos Aires: Editorial Atlántida. 1944

MABRAGAÑA H. Los mensajes. Historia del desenvolvimiento de la Nación Argentina redactada cronológicamente por sus gobernantes, 1810-1910, Tomos III y IV, Comisión nacional del Centenario. Buenos Aires: Talleres Gráficos de la Compañía Gral. de Fósforos. 1910.

MANDRINI, Raúl. Indios y fronteras en el área pampeana (siglos XVI-XIX). Balance y perspectivas. Anuario IEHS, 1992, VII, p. 59-73.

MANDRINI, Raúl. Las fronteras y la sociedad indígena en el ámbito pampeano. Anuario IEHS, 1997,12, p.23-34.

MANDRINI, Raúl (editor) Vivir entre dos mundos. Las fronteras del sur de la Argentina. Siglos XVIII y XIX. Buenos Aires: Taurus. 2006.

MAYO, Carlos A.; LATRUBESSE, Amalia. Terratenientes, soldados y cautivos. La frontera, 1736-1815. Buenos Aires: Biblos. 1998.

NAVARRO FLORIA, Pedro. El salvaje y su tratamiento en el discurso político argentino sobre la frontera sur, 1853-1879. Revista de Indias, 2001, LXI (222), p. 345376.

PEDROTTA, Victoria; LANTERI, Sol. Los "Pampas" de Azul y Tapalqué desde sus orígenes hasta hoy. Una mirada al universo femenino del arte textil. Maná Azul, 2010, Año 3, n 5, p. 60-76.

PESOA MARCILLA, Melisa. Una ciudad para la pampa. Idea, técnica, proyecto y construcción de las ciudades de la provincia de Buenos Aires durante el siglo XIX, Tesis de Máster dirigida por Joaquín Sabaté Bel, Universitat Politècnica de Catalunya, 2012.324p.

QUIJADA, Mónica. La ciudadanización del "indio bárbaro". Políticas oficiales y oficiosas hacia la población indígena de la Pampa y la Patagonia, 1870-1920. Revista de Indias, 1999, LIX (217), p. 675-704. 
Repensando la frontera sur argentina: concepto, contenido, continuidades y discontinuidades de una realidad espacial y étnica (siglos XVIII-XIX), Revista de Indias, 2002, LXII (224), p. 103-142.

RAMOS, Jorge ( ). Fortín. In LIERNUR, J.F. y ALIATA, F. (ed.). Diccionario de Arquitectura en la Argentina. Buenos Aires: Clarín. 2004, p. 99-100

RAONE, Juan Mario. Fortines del desierto. Mojones de civilización. Buenos Aires: Biblioteca del Suboficial. 1969.

RATTO, Silvia. Una experiencia fronteriza exitosa: el negocio pacífico de indios en la provincia de Buenos Aires (1829-1852). Revista de Indias, 2003, LXIII (227), p. 191-222.

SALOMÓN TARQUINI, Claudia, Estrategias de acceso y conservación de la tierra entre los ranqueles (Colonia Emilio Mitre, La Pampa, primera mitad del siglo XX). Mundo agrario. En línea. La Plata: Facultad de Humanidades y Ciencias de la Educación, Universidad Nacional de La Plata, 2010, <http://www.scielo.org.ar/scielo.php?script=sci_arttext\&pid=S1515-59942010000200009\&lng=es\&nrm=iso $>$ ISSN: 1515-5994

SILVESTRI, Graciela. El imaginario paisajístico en el litoral y el sur argentinos. In BONAUDO, Marta (ed.). Liberalismo, estado y orden burgués (1852-1880), Nueva Historia Argentina, tomo IV. Buenos Aires: Editorial Sudamericana. 1999.

SILVESTRI, Graciela. El lugar común. Una historia de las figuras de paisaje en el Río de la Plata, Buenos Aires: Edhasa. 2011.

SILVESTRI, Graciela et al. Las dimensiones de una investigación en historia territorial, Registros, 2008, Año 5, no 5, abril, p. 7-16.

VEZUB, Julio Esteban. Indios y soldados. Las fotografías de Carlos Encina y Edgardo Moreno durante la "Conquista del Desierto". Buenos Aires: El Elefante Blanco. 2002.

YULN, Melina. Factores económicos y transformaciones territoriales en la frontera pampeana: la colonia Coliqueo de Los Toldos en la segunda mitad del siglo XIX, VI Jornadas Interdisciplinarias de Estudios Agrarios y Agroindustriales, CIEA, Facultad de Ciencias Económicas, UBA. 2009.

YULN, Melina. Dibujar el territorio y poblar la nación. Estrategias de ocupación y transformaciones territoriales en el noroeste pampeano (1852-1870), VII Jornadas Interdisciplinarias de Estudios Agrarios y Agroindustriales, CIEA, Facultad de Ciencias Económicas, UBA. 2011.

YULN, Melina. Formas territoriales alternativas. Tierras, indigenas y estado en la frontera pampeana del siglo XIX. Tesis de Maestría dirigida por Graciela Silvestri, Universidad Torcuato Di Tella, 2014. 200 p.

ZWEIFEL, Teresa. Medir lo inconmensurable. Los cambios en los procedimientos para relevar la pampa anterior (1796-1895). Tesis doctoral dirigida por Carla Lois, Universidad Torcuato Di Tella, 2013.210 p. 
(C) Copyright: Melina Yuln, 2017

(c) Copyright Scripta Nova, 2017.

Ficha bibliográfica:

YULN, Melina. Pueblos indígenas en la frontera bonaerense. Los asentamientos de "indios amigos"durante el siglo XIX. Scripta Nova. Revista Electrónica de Geografía y Ciencias Sociales. [En línea]. Barcelona: Universidad de Barcelona, 15 de enero de 2017, vol. XXI, no 554. <http://revistes.ub.edu/index.php/ScriptaNova/article/ view/554>.

ISSN: $1138-9788$. 